\title{
A randomized controlled trial of the effect of supervised progressive cross-continuum strength training and protein supplementation in older medical patients: the STAND-Cph trial
}

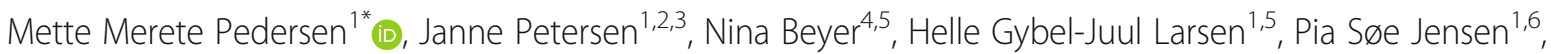
Ove Andersen ${ }^{1,5,7}$, Thomas Bandholm ${ }^{1,8,6}$ and on behalf of the STAND-Cph collaborative group

\begin{abstract}
Background: During hospitalization, older adults (+ 65 years) are inactive, which puts them at risk of functional decline and loss of independence. Systematic strength training can prevent loss of functional performance and combining strength training with protein supplementation may enhance the response in muscle mass and strength. However, we lack knowledge about the effect of strength training commenced during hospitalization and continued after discharge in older medical patients. This assessor-blinded, randomized study investigated the effect of a simple, supervised strength training program for the lower extremities, combined with post-training protein supplementation during hospitalization and in the home setting for 4 weeks after discharge, on the effect on change in mobility in older medical patients.
\end{abstract}

Methods: Older medical patients ( $\geq 65$ years) admitted acutely from their home to the Emergency Department were randomized to either standard care or supervised progressive strength training and an oral protein supplement during hospitalization and at home 3 days/week for 4 weeks after discharge. The primary outcome was between-group difference in change in mobility from baseline to 4 weeks after discharge assessed by the De Morton Mobility Index, which assesses bed mobility, chair mobility, static and dynamic balance, and walking. Secondary outcomes were 24-h mobility, lower extremity strength, gait speed, grip strength and activities of daily living.

Results: Eighty-five patients were randomized to an intervention group $(N=43)$ or a control group $(N=42)$. In the intervention group, 43\% were highly compliant with the intervention. Our intention-to-treat analysis revealed no between-group difference in mobility (mean difference in change from baseline to 4 weeks, $-4.17(95 \% \mathrm{Cl}-11.09 ; 2.74$; $p=0.24$ ) nor in any of the secondary outcomes. The per-protocol analysis showed that the daily number of steps taken increased significantly more in the intervention group compared to the control group (mean difference in change from baseline to 4 weeks, 1033.4 steps ( $95 \% \mathrm{Cl} 4.1 ; 2062.7), p=0.049$, adjusted for mobility at baseline and length of stay; 1032.8 steps (95\% Cl 3.6; 2061.9), $p=0.049$, adjusted for mobility at baseline, length of stay, and steps at baseline).

* Correspondence: mette.merete.pedersen@regionh.dk

${ }^{1}$ Clinical Research Centre, Copenhagen University Hospital Hvidovre,

Kettegaard Alle 30, 2650 Hvidovre, Denmark

Full list of author information is available at the end of the article

(c) The Author(s). 2019 Open Access This article is distributed under the terms of the Creative Commons Attribution 4.0 International License (http://creativecommons.org/licenses/by/4.0/), which permits unrestricted use, distribution, and reproduction in any medium, provided you give appropriate credit to the original author(s) and the source, provide a link to the Creative Commons license, and indicate if changes were made. The Creative Commons Public Domain Dedication waiver (http://creativecommons.org/publicdomain/zero/1.0/) applies to the data made available in this article, unless otherwise stated. 
(Continued from previous page)

Conclusions: Simple supervised strength training for the lower extremities, combined with protein supplementation initiated during hospitalization and continued at home for 4 weeks after discharge was not superior to usual care in the effect on change in mobility at 4 weeks in older medical patients. For the secondary outcome, daily number of steps, high compliance with the intervention resulted in a greater daily number of steps. Less than half of the patients were compliant with the intervention indicating that a simpler intervention might be needed.

Trial registration: ClinicalTrials.gov, NCT01964482. Registered on 14 October 2013. Trial protocol PubMed ID (PMID), 27039381.

Keywords: Older medical patients, Strength training, Cross-continuum, Mobility, Activity

\section{Background}

For many older adults, the ability to live independently is ranked a very important health outcome [1], and independence is considered a prerequisite for control and freedom of choice in daily life [2]. Therefore, it is unfortunate that for many older adults (+ 65 years) hospitalization is linked with an increased risk of mobility limitations, functional decline, and loss of independence [3-5], partly due to preventable events like excessive bed rest or low levels of mobility [6-10]. Nevertheless, older adults spend the majority of their in-hospital time in bed [8, 11-15].

The adverse events due to in-hospital inactivity include loss of muscle mass and strength [16-21], especially in the lower extremities [17, 20, 22, 23]. This loss is very rapid and compared to young adults it takes longer for older adults to regain the loss [24], and impairments in muscle strength and power are influential determinants of mobility problems and disability in older adults $[25,26]$.

It has been reported that functional status at discharge and one month after discharge are associated with longterm outcomes $[27,28]$. Thus, it seems imperative to reduce physical inactivity during hospitalization and to focus on regaining functional performance within the first month after discharge, preferably by initiating an exercise program in the hospital and continuing this program in the home setting after discharge [29-31].

Systematic strength training has shown promising results in preventing loss of strength and functional performance [32-36] and in improving mobility in frail older adults [34] Also, weight-bearing exercises seem preferable to non-weight-bearing exercises [37] and higher intensities superior to lower intensities [38-41]. However, there is a lack of knowledge on the optimal dose and intensity of strength training and the optimal exercises in different settings for older adults [32, 38, 42], and challenges with compliance have been reported [29, 43, 44]. Moreover, combining strength training with protein supplementation may stimulate muscle protein synthesis and thus increase the effects of the response to exercise on muscle mass and strength as seen in healthy older adults [45-47].

Therefore, in this randomized controlled trial in older medical patients, we determined the effect on mobility of a simple, low-technology, supervised, high-intensity, strength training program for the lower extremities, combined with post-training protein supplementation initiated during hospitalization and continued in the home setting for 4 weeks after discharge. We hypothesized that the intervention was superior to usual care.

\section{Methods \\ Study design and participants}

This is the primary trial report of a randomized controlled trial conducted from September 2013 to September 2016 at Copenhagen University Hospital Hvidovre in Denmark and in the participants' own homes (ClinicalTrials.gov identifier, NCT01964482). Patients from three municipalities (Copenhagen, Hvidovre and Broendby) were recruited on week days except during holiday periods. During this period, recruitment was paused for 7 months in the municipality of Copenhagen (January to July 2014) and for 1 month in the municipality of Hvidovre (June 2015) due to lack of staff. A full trial protocol - published before inclusion of the last participant - is available with open access [48]. Briefly, on week days the primary investigator or one of three assistant investigators identified eligible newly admitted patients. Older medical patients $(\geq 65$ years) admitted with acute illness from their own home to the Emergency Department of the hospital were included based on random sampling. Patients were excluded on the following criteria: terminal illness; in treatment for diagnosed cancer; diagnosis of Chronic Obstructive Pulmonary Disease (COPD) and participation in a COPD rehabilitation program; living outside the three included municipalities; inability to speak or understand Danish; inability to cooperate in tests/exercises; transfer to the intensive care unit; isolation-room stay; expected hospitalization lasting $<24 \mathrm{~h}$; or inability to stand. The reporting of this study follows the Consolidated Standards of Reporting Trials (CONSORT) statement, using the extension for non-pharmacological trials [49] and the Consensus on Exercise Reporting Template (CERT) checklist [50]. 


\section{Procedures}

\section{Assessments and randomization}

After inclusion, baseline assessments were performed by one of four outcome assessors at the Acute Medical Admissions Ward or at an internal medicine ward at the hospital. Hereafter, the patients included were randomized to either the intervention group or the control group according to a computer-generated block randomization list developed by the study coordinator [46]. The patients were reassessed in their own homes within the first week following discharge, 4-5 weeks after discharge (primary endpoint and end of intervention) and 6 months after discharge. The primary investigator or one of the three assistant investigators, who are all trained physiotherapists, were outcome assessors and performed all baseline and follow-up assessments. All assessments of a patient were performed by the same investigator whenever logistically possible.

\section{Blinding}

We ensured that the outcome assessors were blinded to group assignment [46] and the randomization list was unavailable to the outcome assessors at all times. The research assistant handled all communication with physiotherapists in charge of supervising the strength training sessions and all logistics in connection with home assessments. Also, all patients were asked not to reveal to the investigators to which group they belonged.

\section{Study groups \\ Control group}

Patients assigned to the control group received standard care during hospitalization and following discharge (for further details, please see Pedersen et al. 2016 [48]).

\section{Intervention group}

Patients assigned to the intervention group received progressive strength training supervised $1: 1$ by a skilled physiotherapist on week days during hospitalization and 3 days per week for 4 weeks in their own home after discharge, since recovery of functioning within the first month after discharge has been shown to be important for long-term outcomes [27]. A total of 12 training sessions (over a maximum of 5 weeks) were provided after discharge. Every training session consisted of a warm-up program for the lower extremities followed by two progressive strength training exercises, a sit-to-stand exercise (STAND) (Fig. 1) followed by a heel raise exercise (heel-raise) (Fig. 2) as outlined in Pedersen et al. 2016 [48]. Both exercises followed predefined models of progression allowing for performance of the exercise from a seated position to performing the exercise unilaterally with extra load (level 1 to level 7/level 8). The STAND progression model was found feasible in a previous study [51].
Both exercises were performed for three sets of 8-12 repetitions to fatigue in each set (8-12 repetition maximum (RM)) [52]. The progression models shown in Figs. 1 and 2 were applied to every single set of both exercises by the supervising physiotherapist. Each training session lasted approximately $20 \mathrm{~min}$ including warm up. Immediately after each training session the patients were asked to consume an oral protein supplement (Nutridrink Compact Protein from Nutricia A/S) containing $18 \mathrm{~g}$ milk-based protein and $300 \mathrm{kcal}$.

Standardization of assessments and intervention To ensure standardization of the intervention, the primary investigator performed pre-intervention meetings with all involved outcome assessors and physiotherapists. At meetings for outcome assessors only, the assessors were introduced to and trained in the assessments to ensure standardization. In addition, before conducting an assessment the outcome assessors observed one or two sessions conducted by the primary investigator. Further, the primary investigator supervised each assessor for an assessment at the hospital and an assessment in a home setting. At meetings with physiotherapists only, the physiotherapists were trained in both the warm-up program and the strength training protocol. Should questions arise during the study, the outcome assessors could contact the primary investigator about the assessments and the physiotherapists could contact a senior physiotherapist about the exercise intervention. Also, a geriatrician could be contacted in the case of medical concerns.

\section{Outcomes}

The outcome assessments were performed on admission (baseline), within the first week after discharge, 4-5 weeks after discharge (primary endpoint), and 6 months after discharge.

\section{Primary outcome measure}

The primary outcome was change in the De Morton Mobility Index (DEMMI) score from baseline to 4 weeks after discharge. The DEMMI is a valid and reliable measure of mobility in older adults assessing bed mobility, chair mobility, static and dynamic balance, and walking [53-56]. The DEMMI is scored from 0 to 100 where 100 represents the highest level of mobility [53, 54] and a score below 62 is considered to reflect limited mobility in community-dwelling older adults [57]. In acute older medical patients, the minimal clinically important difference on the DEMMI score is 10 points $[53,56]$.

\section{Secondary outcome measures}

The secondary outcomes have been described in detail in Pedersen et al. 2016 [48]). Briefly, the secondary outcomes were: 


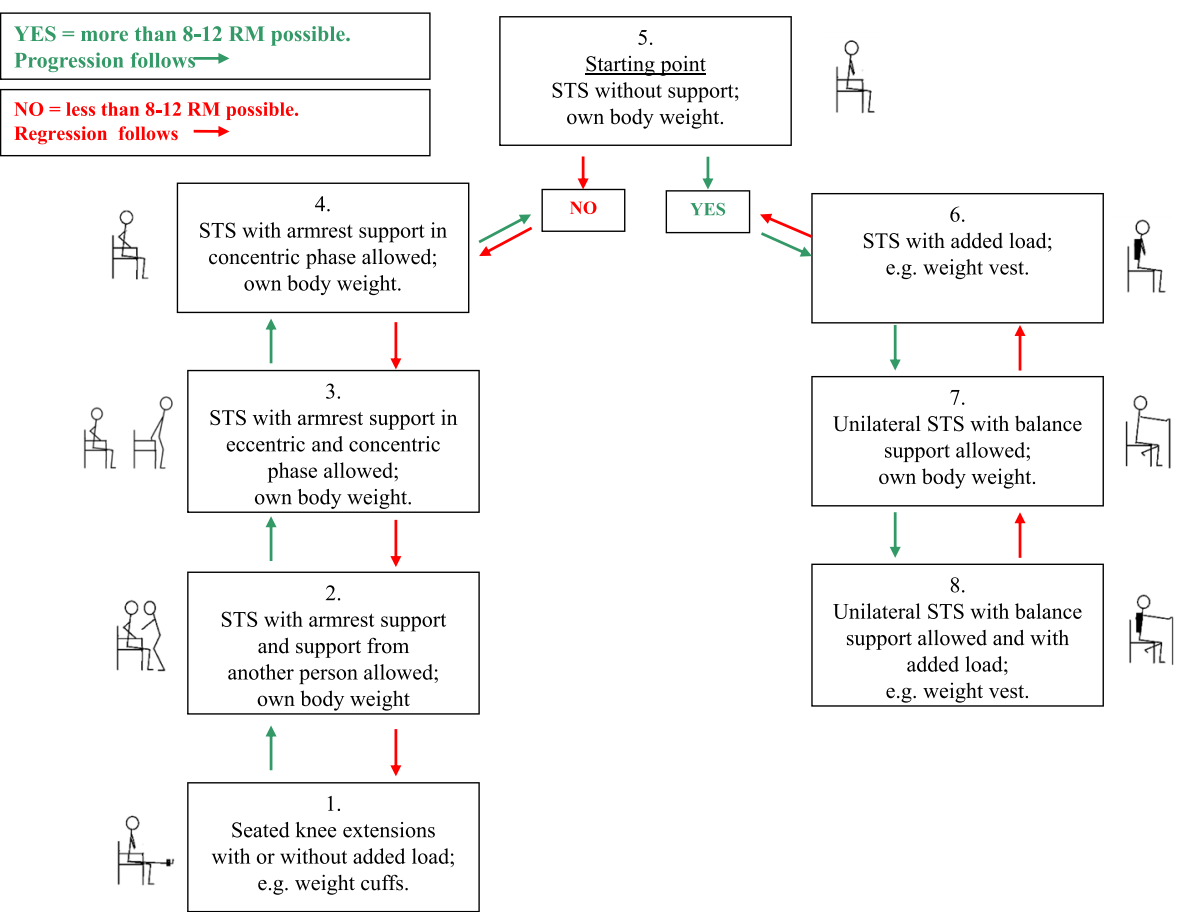

Fig. 1 Progression model for loaded sit-to-stand exercise (STAND). The starting point in STAND in the first session was level 5. The patient was seated in a standard chair with armrests with the feet on the floor at shoulder-width apart and arms crossed at the wrist with the hands placed on the opposite shoulder. The patient was asked to rise to a fully extended position and to sit down at a constant pace and was encouraged verbally to perform as many repetitions as possible. The supervising physiotherapist ensured that each set of the exercise was performed at a level of the model ensuring 8-12 repetition maximum (RM). If extra weight was needed, a weight vest (Titan Box, 1-30 kg) was used. STS, 30-s sitto-stand test. The stick art is the author's own work and was published for the first time in Pedersen et al. PeerJ (2015) 3:e1500; DOI 10.7717/ peerj.1500in and subsequently in Pedersen et al. Trials (2016) 17:176)

1. The 24-h mobility measured by an activPAL3 $3^{\mathrm{ma}}$ activity monitor (PAL Technologies Ltd., Glasgow, UK). The patient wore the activPAL $3^{\text {ma }}$ from inclusion into the study and throughout the entire hospitalization, the first week after discharge, the first week after the 4-week assessment and the first week after the 6-month assessment. The activPAL3 ${ }^{\text {tix }}$ monitors continuously for 7 days and assesses time spent sitting/lying, standing, and walking, and the number of steps taken. During hospitalization, the monitor was replaced after 7 days in the case of hospitalizations extending beyond 7 days. In agreement with an observational study preceding this randomized controlled study [11], and to maximize the number of full days with $24 \mathrm{~h}$ of measurements, we considered a day to be from 12:00 a.m. until 12:00 a.m. to avoid half-day measurements as the accelerometers were normally attached in the morning. Because very few patients are hospitalized for more than 6 days, we only included the first 6 days of hospitalization in the analysis. To avoid skewed days in the analysis, we included only patient-days with more than $20 \mathrm{~h}$ of measurements when studying the distributions of sitting/lying, standing, and walking. The ActivPal $3^{\text {ma }}$ has been shown valid and reliable in measuring posture and transitions in mobility-limited older adults $[58,59]$ and in measuring walking at speeds between $0.67 \mathrm{~m} / \mathrm{s}$ and $1.56 \mathrm{~m} / \mathrm{s}$ [60-62]. The ActivPal $3^{\text {tw }}$ data will be dichotomized into sedentary (sitting/lying) and upright time (walking/standing) according to our protocol [48] if $15 \%$ walk at speeds below $0.67 \mathrm{~m} / \mathrm{s}$, since the percentage error in measuring steps is greater for slow walkers than fast walkers [59-63].

2. Isometric knee extension strength (IKE; $\mathrm{Nm} / \mathrm{kg}$ ) in the dominant leg measured by a handheld dynamometer (Power Track II Commander; JTech Medical, Utah) with the patient seated in a standard chair (height $45 \mathrm{~cm}$ ), arms crossed over the chest and $90^{\circ}$ knee flexion $[64,65]$. The patient was asked to perform three maximal knee extensions ( $5 \mathrm{~s}$ duration, $1 \mathrm{~min}$ apart). The highest value obtained was used as the outcome.

3. The 30-s sit-to-stand test (STS; number performed in $30 \mathrm{~s}$ ) using a standard arm chair (seat height 45 $\mathrm{cm}$ ) [66]. The patient was asked to stand up and sit down as many times as possible in a 30-s period. We used a modified 30-s STS allowing arm 


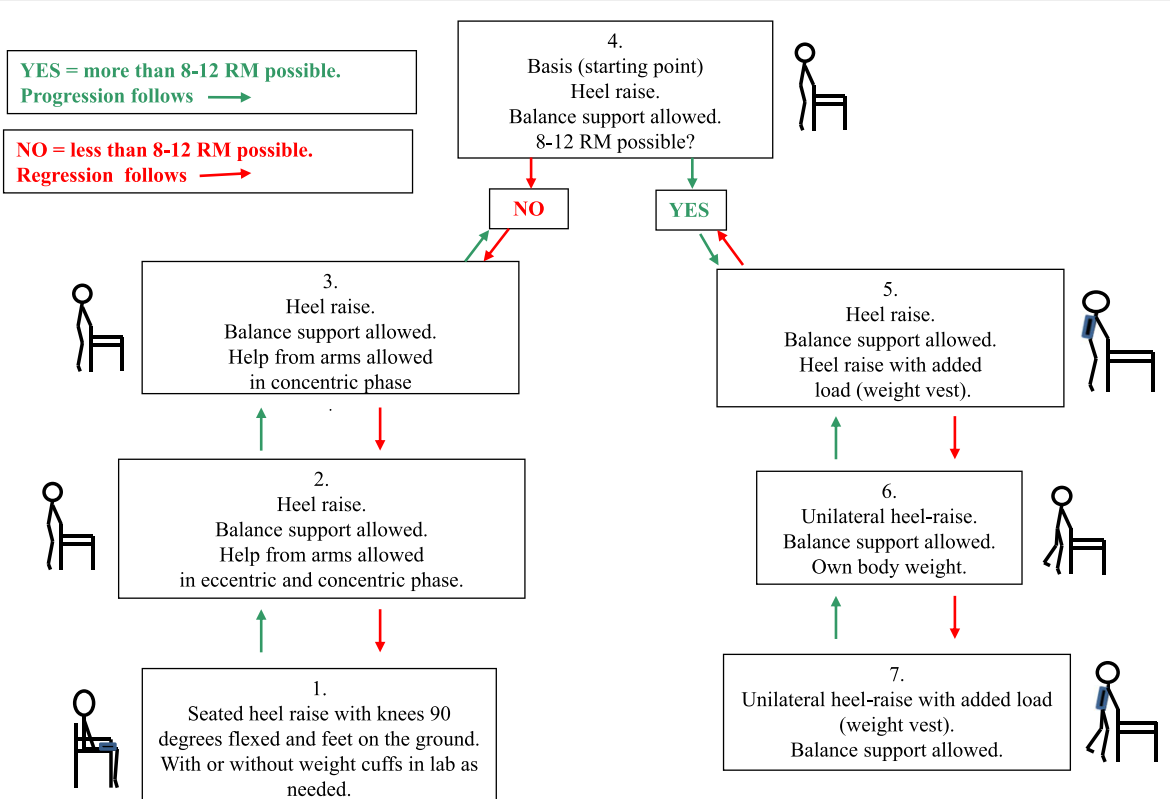

Description of model-procedure

Procedure

- Perform all exercises at a moderate velocity with both the concentric (raising) and the eccentric (lowering) component being

performed over 2 seconds, separated by a 1-second quasi-isometric pause after the concentric and eccentric phases, respectively.

Perform as many repetitions as possible maintaining the same pace to ensure training to contraction failure.

If muscle fatigue is reached within 8-12 repetitions, stay at the same level.

- If muscle fatigue is not reached within 8-12 repetitions, perform the exercise at a lower level.

- If muscle fatigue is reached within more than 12 repetitions, perform the exercise at a higher level

- Aim at 3 sets of 8-12 RM corresponding to training at $60-70 \%$ of 1 RM.

- Allow minimal extra support after 6 non-compensatory repetitions to attain contraction failure - if a proper technique is maintained.

Allow increased speed in the last two repetitions if necessary to ensure training at the highest possible level.

Adjust loads/levels on a set-by-set basis.

- Ensure a 1-minute pause between sets.

Levels - the starting point is level 4 :

Level 1: Put an appropriate weight cuff ( $\geq 0.5 \mathrm{~kg}$ ) in the lap. Lift the heels from the ground as much as possible.

Level 2: From a standing position with balance support lift the heels from the ground and lower the heels using the chair for support

Level 3: From a standing position with balance support lift the heels from the ground and lower the heels using the chair for support in the concentric phase.

Level 4: From a standing position with balance support lift the heels from the ground and lower the heels

Level 5: From a standing position with balance support and wearing a weight vest $(0-30 \mathrm{~kg})$ lift the heels from the ground and lower the

heels.

Level 6: From a standing position on one leg with balance support lift the heels from the ground and lower the heels (shift legs after each

set, aiming at 3 set per leg)

Level 7: From a standing position on one leg with balance support and wearing a weight vest $(0-30 \mathrm{~kg})$ lift the heels from the ground and

lower the heels (shift legs after each set, aiming at 3 set per leg)

Fig. 2 Progression model for loaded heel-raise (heel-raise). The starting point in heel-raise in the first session was level 4. The patient was standing behind a standard chair using the chair for balance support and keeping the feet on the floor at shoulder-width apart. The patient was asked to lift both heels to stand on the forefoot and to lower the heels to a standing position at a constant pace, and was encouraged verbally to perform as many repetitions as possible. The supervising physiotherapist ensured that each set of the exercise was performed at a level of the model ensuring 8-12 repetition maximum (RM). If extra weight was needed, a weight vest (Titan Box, 1-30 kg) was used. The stick art is the author's own work and was published for the first time in Pedersen et al. Trials (2016) 17:176)

rest support for patients who were unable to rise once from the chair with the arms crossed over the chest.

4. Habitual gait speed (HG; m/s) measured on a 4-m course $[67,68]$ from a standing start position (walking aids were allowed). The faster of two walks was used as the outcome. A gait speed below $0.8 \mathrm{~m} / \mathrm{s}$ is considered to reflect poor mobility [69].

5. Hand-grip strength (HGS; kg) in the dominant hand measured with a handheld dynamometer
(Digi-II; Saehan) with the patient seated in a standard armchair (seat height $45 \mathrm{~cm}$ ), with the lower dominant arm placed on the armrest, $90^{\circ}$ elbow flexion and neutral wrist position. The highest value of three maximal squeezes of the handle $(5 \mathrm{~s}$ duration, 1 min apart) was used as the outcome.

6. The Barthel Index 20 (BI) was used as a measure of activities of daily living (ADL) [70]. The BI is scored between 0 and 20 with higher scores indicating less disability in ADL. 


\section{Additional variables}

We collected descriptive variables and possible confounders and modifiers: age, sex, education, living status, history of smoking, use of ambulatory devices, use of municipal help, history of falls during the last year, mobility assessed by the New Mobility Score (NMS) [71, 72], ambulatory capacity assessed by the Cumulated Ambulation Score [73], cognition assessed by the Short OrientationMemory-Concentration test (OMC) [74] and the Mini Mental State Examination [75], depression assessed by the Geriatric Depression Scale (GDS) [76], health status assessed by the EuroQol instrument [77], nutritional state assessed by the Mini Nutritional Assessment [78], self-reported physical activity [79, 80], pain before and after training assessed by the Verbal Ranking Scale (VRS) [81, 82], medications, history of training before admission, and history of municipal training after discharge. In addition to the protocol [48], from January 2015 patients in the intervention group were asked about their satisfaction with the strength training intervention in 5 questions with corresponding 3-4-level rating scales: (1) How satisfied are you with the training intervention? ("Very satisfied"; "Satisfied"; "Dissatisfied"; "Very dissatisfied"; "Don't know"); (2) I have benefitted from the strength training sessions ("Strongly agree"; "Agree; "Disagree; "Strongly disagree; "Don't know); (3) The amount of training was ("Appropriate"; "Too little"; "Too much"; "Don't know"); (4) I will ("Continue training on my own"; "Continue training with others"; "Stop training"; "I don't know"); (5) Are you satisfied with the results of the training? ("Very satisfied"; "Satisfied"; "Dissatisfied"; "Very dissatisfied"; "I don't know"). A research assistant called the participant after completion of the intervention to ask these questions. Also, from the National Patient Registry we obtained data on comorbidities and readmissions. The Charlson Comorbidity Index [83] was calculated based on the International Classification of Diseases, 10th Edition (ICD-10) [84], and we used registry data on hospital admissions and outpatient visits during the 10 years preceding the admission that was related to inclusion in this study.

Exercise diary During each training session the supervising physiotherapist recorded the exercise level, number of repetitions completed, and the extra load added (in kilograms). Pain before and after each training session was recorded using the VRS [81]. The amount of protein consumed and reasons for non-participation were also recorded. Good compliance with the intervention was defined as completion of $80 \%$ of all training sessions with a minimum of two sets performed per session and moderate compliance was defined as completion of $67 \%$ of all training sessions (8 out of 12 sessions) performed with a minimum of two sets per session.

\section{Data management}

Trial data management complied with the rules of the Danish Data Protection Agency and was performed blinded to group allocation. All data were double-entered in Epidata Entry 3.1 (Epidata Associations, Odense, Denmark). Ranges were checked for data values and checked against the case report forms. Data from the activPAL3 ${ }^{\mathrm{TM}}$ monitors were downloaded using the activPAL ${ }^{\mathrm{Tm}}$ Professional software version 7.2.32. All data were exported to SAS Enterprise Guide 7.1 (SAS Institute Inc., Gary, NC, USA).

\section{Sample size}

We estimated our sample size based on unpublished data from a cohort study performed at Hvidovre Hospital in older medical patients, showing mean change in the de Morton Mobility Index [56] score of 1.8 from admission to 4 weeks after discharge and standard deviation of 12.8. A sample of 54 patients was required to detect a 10-point difference (minimal clinically important difference [56]) in the between-group change in the DEMMI score at the 4-week assessment, given a type I error rate of $5 \%$ and power of $80 \%$ for a two-sample $t$ test of a normal mean difference with a two-sided significance level. According to our protocol, we included patients until both groups contained 25 patients assessed for the primary endpoint (4 weeks).

\section{Statistical analyses}

Depending on the distribution of the variables, descriptive data are presented either as means with standard deviations, medians with interquartile ranges or frequencies with percentages. For determining differences between participants who remained in the study and participants who dropped out we used the chi squared $\left(x^{2}\right)$ test to test for difference in sex and Student's $t$ test to test for differences in age and the DEMMI score. Our primary analysis for the primary outcome was a mixed model analysis of the between-group difference in change in the DEMMI score from baseline to 4 weeks after discharge using the SAS procedure PROC MIXED. All randomized patients were analyzed following the intention-to-treat (ITT) principle, using multiple imputation in the case of missing data points, and the analysis was unadjusted (for the number of imputations at each assessment point, please see Additional file 1). We used a fully conditional specification (FCS) regression method in PROC MI for imputation of missing data based on age, group, and all previous assessments or time points. For ActivPal data, only the first day during hospitalization was imputed to avoid imputation for days when the patients were not hospitalized and thereby to account for differences in lengths of stay. This imputation was based on age, group, and baseline DEMMI score. According to the method of Graham et al. [85], we used 100 imputations to avoid a power falloff. The patient 
identification number and municipalities were modeled as random variables, group and time were modelled as fixed factors, and the between-group difference in change in the DEMMI score was estimated from the interaction between the time and the group variable. We also analyzed the effect during hospitalization and the effect after the intervention ended, based on the primary analysis model. Similar analyses were performed for all outcomes with all analyses adjusted for baseline DEMMI score to adjust for the large variation in mobility in older medical patients [86]. Also, to account for imbalances in time spent in hospital, the effect during hospitalization and the effect from baseline to the end of the intervention adjusted for length of hospital stay were analyzed. In addition, a per-protocol (PP) analysis was performed comparing patients who had fulfilled the compliance criteria (80\% of post-discharge sessions completed with a minimum of two sets in each session) with those in the control group who had not dropped out before the 4-week assessment and, thus, would have been able to comply with the intervention if they had been assigned to the intervention group. In the PP analysis, ActivPal data from days 5 and 6 at 6 months were not included in the analysis due to too many missing data. In supplement to the aforementioned analyses, all ITT and PP analyses were conducted with adjustment for baseline values of the outcome of interest. All betweengroup differences are expressed as the average difference in change from baseline to relevant outcome time with corresponding 95\% confidence intervals. All models were investigated for goodness-of-fit (linearity, variance homogeneity, and normal distribution of residuals) by visual inspection of residual plots and were remodeled if necessary. We used SAS Enterprise Guide 7.1 (SAS Institute Inc., Gary, NC, USA) for all statistical analyses and considered $p$ values $\leq 0.05$ to be statistically significant. However, for all analyses evaluating potential modifiers and confounders of the intervention, $p$ values $\leq 0.01$ were used to account for multiple testing.

\section{Results}

A total of 85 patients were included and randomized to the intervention group $(N=43)$ or the control group $(N=42)$. Figure 3 illustrates the flow of patients throughout the study [49]. Between baseline and 4 weeks, twelve patients in the intervention group were lost to follow up (27\%). Reasons for declining to participate any further were lack of information about the extent of the study; lack of time/ too many things going on; being in the middle of a divorce; exercise-induced muscle soreness; and chronic leg pain. Seventeen patients in the control group were lost to follow up (40\%). Reasons for declining to participate any further were impeding surgery; not wishing to continue; lack of time/too many things going on; lack of information; and not wanting to have anything to do with the hospital.
There were no significant baseline differences in age, sex, or DEMMI score between patients lost to follow up and patients remaining in the study at 4 weeks (all $p>0.31$ ). One patient in each of the two groups was lost to follow up between 4 weeks and 6 months. The ActivPal $3^{\text {тм }}$ data was missing for 24 patients during hospitalization (8 patients were lost to follow up, in 2 patients the monitors were not attached due to miscommunication, 1 patient had an allergic reaction to the adhesive padding, 7 patients had monitors lost on the ward, and 6 patients had data for less than $20 \mathrm{~h}$ ); for 29 patients after discharge ( 2 patients took the monitor off, 1 patient had an allergic reaction to the adhesive band, 14 patients were lost to follow up, 10 patients did not want to wear the monitor, 1 patient experienced itching under the monitor, and 1 patient lost the monitor); for 41 patients after the 4 week assessment (27 patients were lost to follow up, 2 patients were not able to cooperate, 1 patient was allergic to the adhesive band, 10 patients did not want to wear the monitor, and 1 patient experienced itching under the monitor); and 46 patients after the 6 months assessment (29 patients were lost to follow up, 2 patients were not able to cooperate, 1 patient was allergic to the adhesive band, 12 patients did not want to wear the monitor, 1 patient experienced itching under the monitor, and 2 patients lost the monitors).

\section{Baseline characteristics}

At baseline, no between-group differences appeared to be clinically relevant (no hypothesis testing was undertaken as suggested by the CONSORT group, Table 1 ). Overall, the patients were 82.3 years of age (SD 7.4), $65.9 \%$ were female, $67.1 \%$ were living alone, and $54 \%$ had an NMS reflecting poor function independency (a score of 0-5) [71]. The majority was admitted to the hospital with pulmonary problems and the median length of stay (LOS) was 4 days.

\section{Outcomes}

At baseline, the participants had an average DEMMI score of 60.7 (SD 16.4) reflecting limited mobility [57]. The between-group differences for the primary and secondary outcome measures are shown in Table 2, and the values for the primary and secondary outcomes at the four assessment points are shown in Table 3.

\section{Primary outcome}

Both the ITT analysis and the PP analysis showed no significant between-group difference in change in the DEMMI score for any of the three periods assessed (baseline to 4 weeks after discharge; baseline to discharge; 4 weeks to 6 months) (Table 2). In addition, no differences were found when adjusting the analyses for baseline DEMMI score or LOS (results not shown). 
Patient flow

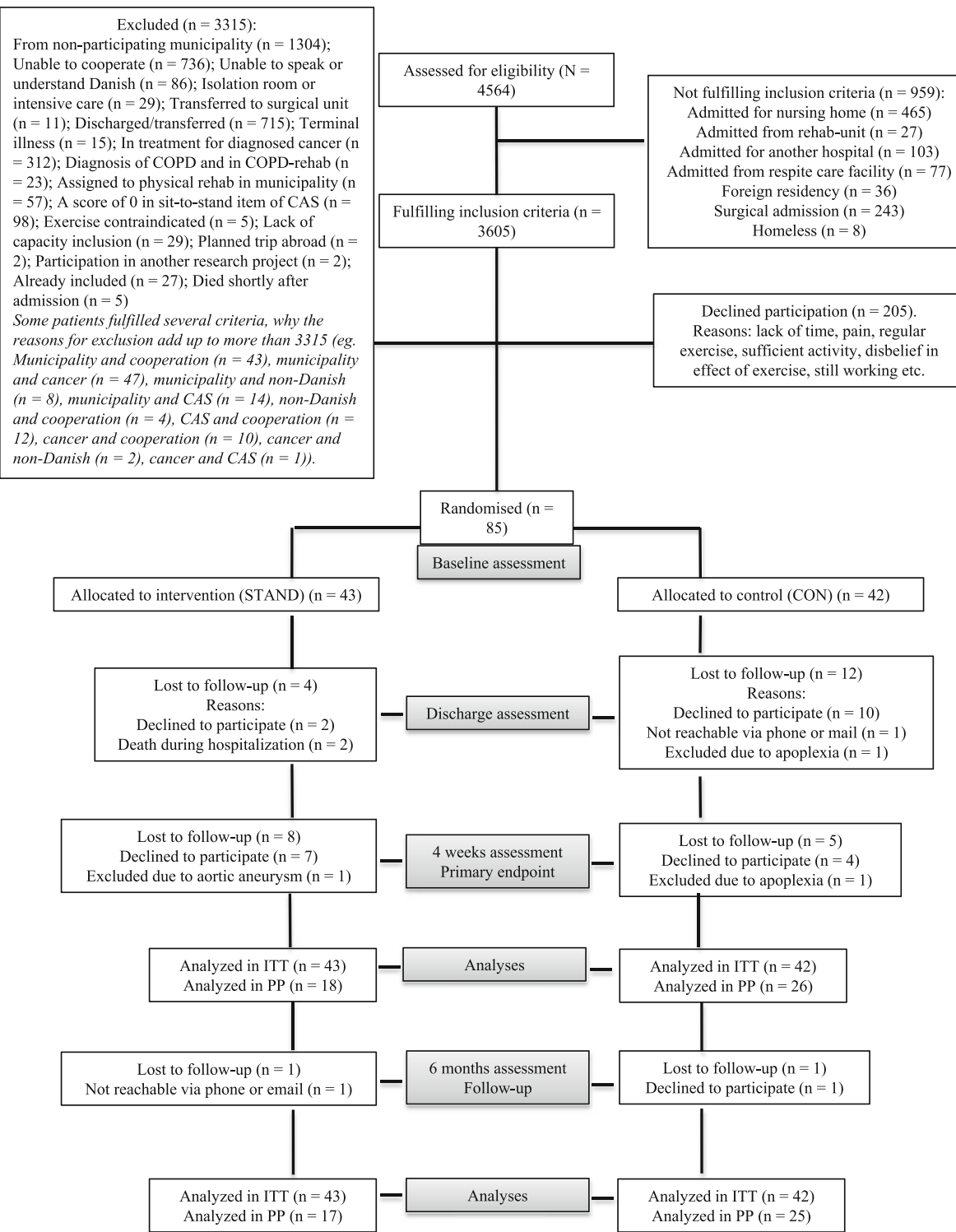

Fig. 3 Flow of patients. COPD, chronic obstructive pulmonary disease; CAS, Cumulated Ambulation Score; STAND, sit-to-stand exercise; ITT, intention to treat; PP, per protocol

However, there was a significant change in DEMMI score from baseline to 4 weeks in both groups in both the ITT analysis (mean difference from baseline to 4 weeks: intervention, 8.3 points $(95 \%$ CI $0.6 ; 16.0), p=$ 0.04 ; control, 11.5 points $(95 \%$ CI 3.5 ; 19.4), $p<0.01$ ) and in the PP analysis (mean difference from baseline to 4 weeks: intervention, 10.6 points $(95 \%$ CI 0.6 ; 20.6), $p=0.04$; control, 11.6 points (95\% CI $2.9 ; 20.3$ ), $p<0.01$ ) (results not shown).

\section{Secondary outcomes}

During hospitalization, the participants spent an average of $21.7 \mathrm{~h}$ per day sedentary (sitting or lying), a median of $1.8 \mathrm{~h}$ in an upright position (standing or walking) and took a median of 702 steps per day. On admission, their knee extension strength was $0.7 \mathrm{Nm} /$ $\mathrm{kg}$ (IQR $0.5 ; 0.9)$, they performed six sit-to-stand transitions in $30 \mathrm{~s}$ (IQR 0; 9), their habitual gait speed was $0.6 \mathrm{~m} / \mathrm{s}$ (IQR 0.4; 0.8), handgrip strength was $28.9 \mathrm{~kg}$ in men (IQR $23.1 ; 37.0)$ and $15.6 \mathrm{~kg}$ in women (IQR 13.0;20.2), and they had a Barthel score of 20 (IQR 18; 20) (Table 1).

For all secondary outcomes, the ITT analyses showed no significant between-group differences in change scores for any of the three periods (baseline to 4 weeks; hospitalization; post intervention) except for an increase in handgrip strength in the intervention group during 
Table 1 Baseline characteristics

\begin{tabular}{|c|c|c|c|}
\hline Descriptive data & Overall $(N=85)$ & Intervention $(N=42)$ & Control $(N=43)$ \\
\hline Age (years) & $82.3(7.4)$ & $82.1(7.4)$ & $82.5(7.5)$ \\
\hline \multicolumn{4}{|l|}{ Sex } \\
\hline Male & $34.1 \%$ & $28.6 \%$ & $39.5 \%$ \\
\hline Female & $65.9 \%$ & $71.4 \%$ & $60.5 \%$ \\
\hline BMl & $25.3(22.3 ; 29.3)$ & $25.3(22.3 ; 29.1)$ & $24.5(22.3 ; 30.0)$ \\
\hline Living alone (yes, \%) & $67.1 \%$ & $69.1 \%$ & $65.1 \%$ \\
\hline \multicolumn{4}{|l|}{ Education (\%) } \\
\hline$<$ High school & $25.9 \%$ & $23.8 \%$ & $27.9 \%$ \\
\hline Skilled & $55.3 \%$ & $54.8 \%$ & $55.8 \%$ \\
\hline High school & $3.5 \%$ & $4.8 \%$ & $2.3 \%$ \\
\hline Graduate & $9.4 \%$ & $9.5 \%$ & $9.3 \%$ \\
\hline Post graduate & $5.9 \%$ & $7.1 \%$ & $4.7 \%$ \\
\hline \multicolumn{4}{|l|}{ Smoking status } \\
\hline Smoking (yes, \%) & $17.7 \%$ & $19.1 \%$ & $16.3 \%$ \\
\hline Previous smoker (yes, \%) & $81.2 \%$ & $78.6 \%$ & $83.7 \%$ \\
\hline \multicolumn{4}{|l|}{ Assistive devices } \\
\hline Walking stick & $25.9 \%$ & $14.3 \%$ & $37.2 \%$ \\
\hline Crutches & $8.2 \%$ & $9.5 \%$ & $6.9 \%$ \\
\hline Walker & $34.1 \%$ & $28.6 \%$ & $39.5 \%$ \\
\hline Wheel chair & $3.5 \%$ & $4.8 \%$ & $2.3 \%$ \\
\hline Furniture support & $28.6 \%$ & $29.3 \%$ & $27.9 \%$ \\
\hline Scooter & $5.9 \%$ & $2.4 \%$ & $9.3 \%$ \\
\hline \multicolumn{4}{|l|}{ Use of municipal help } \\
\hline Assistance from community (yes, \%) & $62.4 \%$ & $61.9 \%$ & $62.8 \%$ \\
\hline Personal help (yes, \%) & $11.8 \%$ & $19.1 \%$ & $4.7 \%$ \\
\hline Cleaning (yes, \%) & $20.0 \%$ & $16.7 \%$ & $23.3 \%$ \\
\hline Fall during past year (yes, \%) & $51.8 \%$ & $52.4 \%$ & $51.2 \%$ \\
\hline Short Falls Efficacy Scale (score) & $8(7 ; 10)$ & $8(7 ; 11)$ & $8(7 ; 9)$ \\
\hline \multicolumn{4}{|l|}{ Admission diagnosis (category) } \\
\hline Pulmonary & $43.5 \%$ & $45.2 \%$ & $41.9 \%$ \\
\hline Cardiovascular & $25.9 \%$ & $21.4 \%$ & $30.2 \%$ \\
\hline Other ${ }^{a}$ & $30.6 \%$ & $33.3 \%$ & $27.9 \%$ \\
\hline \multicolumn{4}{|l|}{ Charlson Comorbitity Index (n) } \\
\hline 0 & $18.8 \%$ & $21.4 \%$ & $16.3 \%$ \\
\hline $1-2$ & $52.9 \%$ & $47.6 \%$ & $58.1 \%$ \\
\hline $3+$ & $28.2 \%$ & $31.0 \%$ & $25.6 \%$ \\
\hline Length of stay (days) & $4(2 ; 7)$ & $4.5(2.5 ; 7.0)$ & $4(2 ; 6)$ \\
\hline \multicolumn{4}{|l|}{ New Mobility Score (points) } \\
\hline Admission & $5(2 ; 7)$ & $4(2 ; 7)$ & $5(2 ; 9)$ \\
\hline In retrospect & $7(5 ; 9)$ & $7(6 ; 9)$ & $6(5 ; 9)$ \\
\hline
\end{tabular}

Variables are presented as mean (SD), median (IQR) or percentages depending on the distribution of the variable.

${ }^{a}$ Endocrinological, neurological, hepato-nephrological, gastrological, dermatological 
Table 2 Between-group differences in change scores from baseline to discharge, 4 weeks, and 6 months ( $\Delta$ intervention- $\triangle$ control)

\begin{tabular}{|c|c|c|c|c|c|c|}
\hline Primary outcome & Baseline to 4 weeks & $P$ & Baseline to discharge & $P$ & 4 weeks to 6 months & $P$ \\
\hline DEMMI, score (ITT) & $-4.17(-11.09 ; 2.74)$ & 0.24 & $-0.51(-6.51 ; 5.49)$ & 0.87 & $2.97(-2.81 ; 8.76)$ & 0.31 \\
\hline DEMMI, score (PP) & $-1.00(-9.28 ; 7.27)$ & 0.81 & $4.70(-3.30 ; 12.70)$ & 0.25 & $1.55(-2.86 ; 5.95)$ & 0.49 \\
\hline \multicolumn{7}{|l|}{ Secondary outcomes } \\
\hline \multicolumn{7}{|l|}{ 24-h activity measures (ActivPal) } \\
\hline Upright time, h/day (ITT) & $0.06(-0.89 ; 1.02)$ & 0.90 & $-0.59(-1.16 ; 0.01)$ & 0.046 & $0.21(-1.18 ; 160)$ & 0.77 \\
\hline Upright time, h/day (PP) & $0.25(-0.61 ; 1.11)$ & 0.57 & $-0.55(-1.14 ; 0.05)$ & 0.07 & $-0.002(-1.36 ; 1.37)$ & 1.00 \\
\hline Lying/sitting, h/day (ITT) & $0.03(-1.02 ; 1.09)$ & 0.95 & $0.46(-0.21 ; 1.14)$ & 0.18 & $-0.001(-1.35 ; 1.34)$ & 0.99 \\
\hline Lying/sitting, h/day (PP) & $-0.09(-1.08 ; 0.90)$ & 0.86 & $0.28(-0.42 ; 0.98)$ & 0.44 & $-0.19(-1.45 ; 1.07)$ & 0.77 \\
\hline Steps, $n(I T T)$ & $472.48(-536.44 ; 1481.41)$ & 0.36 & $117.76(-465.37 ; 700.90)$ & 0.69 & $339.12(-1152.00 ; 1830.25)$ & 0.65 \\
\hline Steps, $n$ (PP) & $999.19(-23.88 ; 2022.25)$ & 0.05 & $303.02(-272.84 ; 878.88)$ & 0.30 & $44.59(-1658.60 ; 1747.79)$ & 0.96 \\
\hline Adjusted for DEMMI and LOS & $1033.40(4.13 ; 2062.66)$ & 0.049 & & & & \\
\hline Adjusted for DEMMI, steps, and LOS & $1032.77(3.60 ; 2061.94)$ & 0.049 & & & & \\
\hline \multicolumn{7}{|l|}{ Physical performance measures } \\
\hline $\mathrm{KES}, \mathrm{Nm} / \mathrm{kg}(\mathrm{ITT})$ & $0.11(-0.02 ; 0.24)$ & 0.09 & $0.08(-0.05 ; 0.20)$ & 0.24 & $-0.09(-0.20 ; 0.02)$ & 0.11 \\
\hline KES, Nm/kg (PP) & $0.13(-0.02 ; 0.29)$ & 0.09 & $0.10(-0.07 ; 0.27)$ & 0.23 & $-0.11(-0.23 ;-0.002)$ & 0.047 \\
\hline STS, $n$ (ITT) & $0.04(-1.88 ; 1.96)$ & 0.97 & $0.33(-1.22 ; 1.87)$ & 0.68 & $1.28(-0.76 ; 3.31)$ & 0.22 \\
\hline $\mathrm{STS}, n$ (PP) & $-0.01(-2.29 ; 2.27)$ & 1.00 & $0.21(-1.96 ; 2.39)$ & 0.85 & $1.45(-0.94 ; 3.84)$ & 0.23 \\
\hline $\mathrm{GS}, \mathrm{m} / \mathrm{s}(\mathrm{ITT})$ & $0.02(-0.06 ; 0.10)$ & 0.64 & $0.07(-0.003 ; 0.15)$ & 0.06 & $0.02(-0.06 ; 0.11)$ & 0.57 \\
\hline $\mathrm{GS}, \mathrm{m} / \mathrm{s}(\mathrm{PP})$ & $0.04(-0.07 ; 0.15)$ & 0.45 & $0.11(0.004 ; 0.22)$ & 0.04 & $0.02(-0.08 ; 0.11)$ & 0.74 \\
\hline $\mathrm{HG}, \mathrm{kg}(\mathrm{ITT})$ & $0.49(-1.40 ; 2.39)$ & 0.61 & $1.86(0.49 ; 3.23)$ & 0.008 & $0.17(-1.46 ; 1.80)$ & 0.84 \\
\hline $\mathrm{HG}, \mathrm{kg}(\mathrm{PP})$ & $0.75(-1.37 ; 2.87)$ & 0.48 & $2.05(0.32 ; 3.77)$ & 0.02 & $-0.28(-2.11 ; 1.55)$ & 0.76 \\
\hline Barthel, score (ITT) & $-0.09(-0.83 ; 0.66)$ & 0.82 & $-0.26(-0.87 ; 0.34)$ & 0.40 & $0.30(-0.11 ; 0.70)$ & 0.16 \\
\hline Barthel, score (PP) & $0.44(-0.42 ; 1.31)$ & 0.30 & $0.02(-0.65 ; 0.70)$ & 0.94 & $0.20(-0.20 ; 0.61)$ & 0.33 \\
\hline
\end{tabular}

Unadjusted values are shown for all comparisons and adjusted values are shown where these differ from the unadjusted analyses. All values are given as mean (95\% confidence interval). For the number of imputations at different time points for the primary and secondary outcomes please see Additional file 1

$I T T$ intention to treat $(N=85), P P$ per protocol $(N=18$ in intervention group (only those compliant with the intervention); $N=26$ in control group), $D E M M I$ baseline value of De Morton Mobility Index, steps: baseline value of steps, LOS length of stay, KES knee extension strength, STS 30-s sit-to-stand, GS gait speed, HG hand grip strength, Barthel Barthel Index

hospitalization in both the unadjusted and the adjusted analyses (Table 2). The PP analyses showed that between baseline and 4 weeks post discharge, the daily number of steps taken increased significantly more in the intervention group (difference in change from baseline to 4 weeks, 1033.40 (95\% CI 4.13; 2062.66); $p=0.049$ adjusted for DEMMI score at baseline and length of stay; 1032.77 (95\% CI 3.60; 2061.94); $p=0.049$ adjusted for DEMMI score at baseline, steps at baseline, and length of stay) compared to the control group and increased more in gait speed and handgrip strength during hospitalization (Table 2). Overall, there was a significant increase in STS from baseline to 4 weeks (mean difference from baseline to 4 weeks, overall: ITT analysis, 2.9 (95\% CI 1.3; 4.7), $p=0.001$; PP analysis, 3.0 (95\% CI 0.6; 5.3), $p=0.01$ ). Also, there was a significant change within both groups in the ITT analysis (mean difference from baseline to 4 weeks: intervention, 3.1 (95\% CI $0.5 ; 5.6), p=0.02$; control, 2.7 (95\% CI 0.3; 5.2), $p=0.03$ ) and in the control group in the PP analysis (mean difference from baseline to
4 weeks: intervention, 3.0 (95\% CI $-0.8 ; 6.9), p=0.12$; control, 3.0 (95\% CI 0.2; 5.9), $p=0.04$ ). There were no withingroup in gait speed, handgrip strength, knee extension strength, or ADL (results not shown).

\section{Compliance and satisfaction with the intervention}

The majority of the patients started the intervention between 0 and 2 days after admission (78.8\%) - range $0-4$. Overall, $43 \%(18 / 42)$ of the patients randomized to the intervention group were very compliant with the intervention $(80 \%$ of sessions performed with two sets of eight $\mathrm{RM})$. Of those who remained in the study at 4 weeks, $60 \%$ $(18 / 30)$ were very compliant and $23 \%(7 / 30)$ were moderately compliant with the intervention (minimum 8 out 12 (67\%) sessions performed with two sets of eight RM). All patients consumed the amount of protein stated in the protocol. Between week 1 and week 4 of the intervention, there was a general increase in the level of exercise performed in both the sit-to-stand exercise and the heel-raise exercise. Thus, in the sit-to-stand exercise, $20 \%$ more 
Table 3 Primary and secondary outcomes at four assessment points (ITT) (non-imputed data)

\begin{tabular}{|c|c|c|c|c|c|c|c|c|}
\hline & $N$ & Hospitalization & N & Discharge & N & 4 weeks & $N$ & 6 months \\
\hline & \multicolumn{8}{|c|}{ Intervention $(N=42)$} \\
\hline De Morton Mobility Index (points) & 42 & $63.5(16.4)$ & 37 & $69.8(16.5)$ & 30 & $71.9(15.7)$ & 27 & $70.9(15.5)$ \\
\hline \multicolumn{9}{|l|}{ 24-h mobility (h/day) } \\
\hline Lying/sitting & 36 & $21.8(1.2)$ & 31 & $20.6(1.3)$ & 25 & $19.7(1.8)$ & 22 & $19.4(1.9)$ \\
\hline Uptime & 36 & $1.4(01.0 ; 1.8)$ & 31 & $3.2(1.8 ; 3.7)$ & 25 & $4.0(3.0 ; 5.2)$ & 22 & $4.1(2.7 ; 5.3)$ \\
\hline Standing & 36 & $1.2(0.8 ; 1.7)$ & 31 & $2.5(1.5 ; 3.1)$ & 25 & $2.8(2.4 ; 4.5)$ & 22 & $3.1(2.2 ; 4.4)$ \\
\hline Walking & 36 & $0.2(0.1 ; 0.3)$ & 31 & $0.5(0.3 ; 0.8)$ & 25 & $0.9(0.4 ; 1.0)$ & 22 & $0.9(0.4 ; 1.1)$ \\
\hline Steps (n/day) & 36 & $660(264 ; 1285)$ & 31 & $1962(1114 ; 3219)$ & 25 & $4147(1471 ; 4683)$ & 22 & $3515(1751 ; 4805)$ \\
\hline Transitions (n up-down/day) & 36 & $50(41 ; 82)$ & 31 & $57(46 ; 78)$ & 25 & $54(47 ; 64)$ & 22 & $56(43 ; 78)$ \\
\hline Isometric knee extension (Nm/kg) & 42 & $0.7(0.5 ; 0.9)$ & 36 & $0.7(0.5 ; 0.9)$ & 29 & $0.8(0.6 ; 1.0)$ & 26 & $0.8(0.6 ; 0.9)$ \\
\hline 30-s Sit-to-stand test (reps) & 40 & $5.5(0$ 9.5) & 37 & $8(5 ; 11)$ & 30 & $9.5(6 ; 12)$ & 27 & $10(5 ; 12)$ \\
\hline 30-s Sit-to-stand test mod. (reps) ${ }^{a}$ & 11 & $5(2 ; 7)$ & 6 & $6.5(5 ; 8)$ & 5 & $4(4 ; 9)$ & 5 & $7(4 ; 8)$ \\
\hline Habitual Gait Speed (m/s) & 41 & $0.6(0.4 ; 0.8)$ & 37 & $0.7(0.6 ; 0.9)$ & 30 & $0.7(0.6 ; 0.9)$ & 27 & $0.7(0.6 ; 0.9)$ \\
\hline Hand grip strength (kg) & 42 & $21.5(10.3)$ & 38 & $23.5(9.9)$ & 30 & $23.5(10.0)$ & 27 & $24.0(10.2)$ \\
\hline \multirow[t]{2}{*}{ Barthel Index 20 (points) } & 42 & $20(19 ; 20)$ & 37 & $20(19 ; 20)$ & 30 & $20(20 ; 20)$ & 27 & $20(19 ; 20)$ \\
\hline & \multicolumn{8}{|c|}{ Control $(N=42)$} \\
\hline De Morton Mobility Index (points) & 43 & $58.1(16.2)$ & 28 & $64.9(14.2)$ & 26 & $69.5(15.7)$ & 25 & $65.1(15.8)$ \\
\hline \multicolumn{9}{|l|}{ 24-h mobility (h/day) } \\
\hline Lying/sitting & 25 & $21.5(1.5)$ & 25 & $18.0(2.1)$ & 19 & $20.3(1.7)$ & 17 & $19.9(1.9)$ \\
\hline Uptime & 25 & $1.8(1.1 ; 2.8)$ & 25 & $3.7(2.0 ; 4.5)$ & 19 & $3.4(2.3 ; 4.2)$ & 17 & $3.9(2.7 ; 4.6)$ \\
\hline Standing & 25 & $1.7(1.0 ; 2.1)$ & 25 & $3.1(1.5 ; 4.0)$ & 19 & $2.7(1.6 ; 3.7)$ & 17 & $2.9(2.1 ; 3.8)$ \\
\hline Walking & 25 & $0.2(0.1 ; 0.6)$ & 25 & $0.5(0.3 ; 0.6)$ & 19 & $0.6(0.5 ; 0.9)$ & 17 & $0.6(0.4 ; 0.9)$ \\
\hline Steps (n/day) & 25 & $754(187 ; 2352)$ & 25 & $1961(1370 ; 2791)$ & 19 & $2800(1607 ; 3509)$ & 17 & $2319(1300 ; 4092)$ \\
\hline Transitions (n up-down/day) & 25 & $47(26 ; 68)$ & 25 & $46.7(38 ; 65)$ & 19 & $51(36 ; 64)$ & 17 & $57(39 ; 69)$ \\
\hline Isometric knee extension (Nm/kg) & 40 & $0.6(0.5 ; 0.8)$ & 27 & $0.6(0.4 ; 0.8)$ & 26 & $0.57(0.44 ; 0.75)$ & 23 & $0.6(0.5 ; 0.7)$ \\
\hline 30-s Sit-to-stand test (reps) & 39 & $6(0 ; 9)$ & 28 & $8.5(3.5 ; 10)$ & 26 & $7.5(5 ; 12)$ & 24 & $6(3 ; 11.5)$ \\
\hline 30-s Sit-to-stand test mod (reps) ${ }^{a}$ & 10 & $7.5(4 ; 9)$ & 4 & $5.5(3.5 ; 7)$ & 3 & $7(6 ; 9)$ & 4 & $6(4 ; 8.5)$ \\
\hline Habitual Gait Speed (m/s) & 41 & $0.6(0.5 ; 0.8)$ & 29 & $0.7(0.5 ; 0.8)$ & 26 & $0.64(0.54 ; 0.87)$ & 25 & $0.6(0.5 ; 0.8)$ \\
\hline Hand grip strength (kg) & 43 & $21.1(8.7)$ & 29 & $21.8(8.9)$ & 26 & $22.4(8.7)$ & 25 & $21.8(8.4)$ \\
\hline Barthel Index 20 (points) & 43 & $19(18 ; 20)$ & 29 & $20(19 ; 20)$ & 26 & $20(19 ; 20)$ & 25 & $20(19 ; 20)$ \\
\hline
\end{tabular}

Variables are presented as mean (SD) or median (IQR) depending on the distribution of the variables $I T T$ intention to treat, reps repetitions

${ }^{a}$ Modified version where the use of the armrests is allowed

patients trained at levels 6-7 in week 4 compared to week 1 , and in the heel-raise exercise, $24 \%$ more patients trained at levels 5-7 in week 4 compared to week 1 . Also, in both exercises those training with a weighted vest (STAND level 6, heel-raise level 5) increased their load by $1.5 \mathrm{~kg}(p=<0.01)$ and $2 \mathrm{~kg}(p<0.01)$, respectively. None of the patients reported an increase in pain during the training sessions and no adverse events were reported.

Twenty-five patients from the intervention group were asked about their satisfaction with the intervention. The majority were satisfied or very satisfied $(88 \%)$ with the intervention, and two thirds (68\%) were satisfied or very satisfied with the results of the intervention. The majority $(17 / 25)$ felt they had benefitted from the strength training sessions and that the amount of training was appropriate (20/25). Also, 16/25 said they would continue training either alone or with others.

There was no difference between the groups in the number of readmissions between discharge and 4 weeks and between discharge and 6 months. Also, there was no difference between the groups in the number of days hospitalized between discharge and 4 weeks and between discharge and 6 months (results not shown). 


\section{Discussion}

This randomized controlled trial investigated the efficacy of a simple, supervised, strength training program for the lower extremities, combined with post-training oral protein supplementation, initiated during hospitalization and continued in the home setting for 4 weeks after discharge in older medical patients admitted with acute illness. The main finding was that no effect of the intervention was seen on mobility assessed by the DEMMI score at any of the investigated time points. However, there was a significant increase in the number of steps taken in the intervention group as compared to the control group in our perprotocol analysis. Overall, $43 \%$ of the patients were highly compliant with the intervention and there was a general increase in the level of exercise performed in both exercises. None of the intervention group patients reported an increase in pain during the exercises and most of them expressed satisfaction with the intervention.

The intervention was not superior to usual care in improving mobility (DEMMI) from baseline to 4 weeks. However, both groups improved their mobility and the improvement reached beyond a clinically important difference [56] in the control group in the intention-totreat analysis and in both groups in the per-protocol analysis. Also, there was no effect on mobility during hospitalization. This is in agreement with previous studies in geriatric patients showing no effect on mobility, assessed by the DEMMI score [87], nor on functional outcomes [88] of an in-hospital, progressive, strength training program. Several reasons for the lack of effect on our primary outcome can be suggested.

Firstly, the intervention had a relatively short duration. It is likely that longer training periods are required to benefit older adults. Studies by Hvid et al. [16, 89] have shown that older adults are more susceptible to periods of inactivity and require more time than younger adults to fully recover. Also, Jadczak et al. recommend interventions with a duration of at least 2.5 months [90]. Accordingly, a systematic review by Valenzuela et al. [36] concludes that progressive resistance training in older nursing home residents is efficient in improving strength and functional performance despite advanced age, chronic diseases, sedentary habits, and functional disabilities. However, all interventions investigated by Valenzuela et al. had a duration of at least 2 months [36]. Equivalently, previous studies have identified an effect on both strength and functional abilities of 10 weeks of supervised, progressive, lower extremity resistive exercises using own weight and Therabands in both frail older adults living in a care facility [91] and communitydwelling older adults [92]. Equal to our study, both studies used 3-weekly training sessions, but slightly more extensive programs (4-8 exercises) $[91,92]$. A systematic review by Borde et al. looking at resistance training in healthy older adults found that the training period, the intensity, and the total time per repetition under tension are all parameters of significance for the effect on muscle strength with the largest effect sizes seen for the longest periods (50-53 weeks), intensities of $70-79 \%$ of $1 \mathrm{RM}$, and a total time under tension per repetition of 6 $\mathrm{s}$ [93]. While the intensity and time under tension recommended by Borde et al. [93] were used in our intervention, we were far from the optimal period presented (50-53 weeks). However, it is questionable whether these recommendations can be followed in newly discharged, older medical patients. Admitted with acute illness. Therefore, we chose a minimal treatment approach focusing on the initial 4 weeks after discharge. Despite a much shorter training period of only 4 weeks, we experienced a substantial drop out rate $(28 \%)$ between baseline and 4 weeks and less than half of the remaining participants were very compliant with the intervention (43\%), indicating that participation would have been even lower in longer interventions.

Secondly, even though the DEMMI has been shown valid and reliable in measuring mobility in both older medical patients and in community-dwelling older adults $[53,54,56]$, and has the ability to measure change in mobility after hospital discharge [56], the patients in that validation sample had much poorer mobility than our participants. Only half of the participants had a baseline DEMMI score below 62, reflecting limited mobility. The functions causing most participants difficulties were related to static and dynamic balance, i.e. tandem stand with closed eyes, walking four steps backwards, and jumping [94]. Obtainment of a significant betweengroup difference in favor of the intervention group would have required that the intervention group participants had learned these three functions, which is highly unlikely based on the provided intervention of sit-tostand and heel-raise exercises. Thus, for the intervention chosen, the DEMMI score may not have been the best choice of primary outcome. Also, the intervention proposed may not be suitable for all patients, and it is worth considering stratifying patients to different interventions according to their mobility difficulties. Accordingly, a recent umbrella review [90] investigating the effect of exercise interventions in pre-frail, community-dwelling, older adults found inconclusive results in the effect on mobility of both multi-component exercises and resistance exercises and suggested that only personalized exercises are effective in improving mobility.

Overall, we found no or very few between-group differences for the secondary trial outcomes. We found a difference in hand grip strength and gait speed during hospitalization in favor of the intervention group and a difference in the change in daily number of steps taken between baseline and 4 weeks in our per-protocol analysis. 
Previous studies have also reported improvement in functional performance measures during hospitalization [95, 96]. However, in accordance with these studies [95, 96] the patients in the present study had poor performance at discharge - their knee extension strength was at the threshold level for independent ability to perform activities of daily living [97], putting them at increased risk of future mobility limitations [98]. Also, their hand grip strength and walking speed were at levels indicating mobility limitations [69]. These low levels of functional performance at discharge are worthy of concern, since functioning has been linked with future risk of falls, functional decline [99], mobility and ADL disability [68, 100, 101], hospital readmissions [28], and death $[67,99,102]$. Older adults see mobility related to everyday functioning as vital to their health and as an indicator of wellbeing and independence enabling them to participate in life as they know it and therefore affecting more that the physical aspects of their life [103]. This underlines the importance of trying to counteract further mobility decline in connection with hospitalization, to help older adults maintain their independence. Like our study, Tibaek et al. [88] found no effect on mobility or of strength training in addition to standard physiotherapy. Also, Oestergaard et al. [87] found no effect of an in-hospital, chair-based, exercise program on mobility and muscle strength.

During hospitalization the participants took a median of 700 steps daily. This small number of steps during hospitalization has been linked to hospital-associated functional decline [104]. Acknowledging that this was a secondary finding, we observed a significant betweengroup difference in change in the number of steps taken between baseline and 4 weeks in favor of the intervention group in our per-protocol analysis. At 4 weeks the control group took a median of 2800 steps compared to 4100 in the intervention group (Table 3). This difference is promising, since Floegel et al. [105] found that each 1000 additional steps in the post-discharge period in older women with heart failure was associated with better physical performance. Also, Breen et al. [22] found that reducing the daily number of steps in healthy older adults by 1400 /day over a fortnight led to a $4 \%$ reduction in leg lean mass, modest increases in inflammation markers, and altered insulin sensitivity. Although the present study did not show an effect on either mobility or functional performance measures, the effect on the number of steps taken is promising. Merely focusing on enhancing the number of steps taken during hospitalization and post discharge could be a goal for future studies, thus lowering the requirements for acutely ill older adults who might find themselves unable to exercise [29]. In addition, an increase in the number of steps taken during hospitalization is associated with shorter length of stay [106], while a decline is associated with greater risk of death within 2 years after discharge [107]. Accordingly, an association has been shown between steps per day post discharge and 30-day readmission rate [108]. In addition, Brown and co-authors [109] found that factors like weakness, need for assistance, lack of interest from staff, and structural barriers are reasons for inactivity in older medical patients ( $\geq 75$ years). Thus, based on the findings from the present trial, we have changed our focus from exercise to walking, to increase intervention compliance. In an ongoing study, we investigate the effect of an intervention including a physical component (i.e. promoting walking) and a component focusing on overcoming structural barriers [110].

\section{Strengths and limitations}

Study strengths included that our intervention was initiated at the hospital and continued at home a few days after discharge, as well as choosing a minimally timeconsuming treatment approach taking into account its implementation in a busy care-setting. Acutely hospitalized older adults may prefer exercise to be initiated in the hospital or shortly after discharge. Also, Franco and co-authors found that exercise at home, an improvement in the ability to undertake daily tasks, and not having to use transportation were the three most important attributes for engaging in physical activity among communitydwelling older adults with a history of falls or selfreported mobility disability [111]. Thus, the fact that our invention took place in the participants' own homes shortly after discharge may have enhanced compliance. However, we do not have data to support this hypothesis.

Another strength of our study is that we have tried to overcome the previously reported lack of knowledge on the optimal nature and dose of exercise in older adults [32, 38, 42]. According to a recent review [112], low intensities are often the first choice among physiotherapists, as this is perceived to be safer. Low intensities, though, may be inadequate to achieve optimal effects on functional performance [41], which is why we wanted to investigate whether higher intensities could be performed by older medical patients without inducing adverse events. Since we found few studies investigating the effect of a cross-continuum program initiated during hospitalization and continued after discharge [29, 43], and due to problems with compliance in these studies, we chose a program with full supervision from trained staff. A 4-week period was chosen since it has previously been reported that recovering function within the first month after discharge is of importance for long-term outcomes [27]. Also, a study in older clients in home care found that structured exercise programs are not the preferred activity of these older adults [113], which is why a 4-week program may be more acceptable than a program of longer duration. Additionally, a previous study in older hospitalized adults showed positive effects of exercise therapy performed during the first 4 weeks 
after discharge [43], leading us to believe that 4 weeks might be sufficient in inducing an effect. Protein was chosen as an integrated part of the strength training intervention. Both resistance training and amino acids can stimulate an anabolic response [114] and the two in combination have been shown to enhance the muscular response to exercise in healthy older adults [45-47]. The provided protein supplementation was intended to boost anabolism. However, it is unclear whether it has merely reduced an existing protein deficit since less than half of our participants could be considered to have a normal nutritional state on admission. Nevertheless, since older adults need a greater amount of daily protein than young adults to maintain muscle mass, and older adults with acute or chronic diseases or marked malnutrition, need even more [115], our intention was to fill out a potential protein gap.

A limitation in our study was that a substantial number of participants dropped out between baseline and 4 weeks $(27 \%)$ - half of these $(N=12)$ dropped out between the admission and the discharge assessment. However, between baseline and 4 weeks the number of drop outs was smaller in the intervention group than in the control group, indicating that the intervention itself was not the reason for dropping out. This is in line with previous studies reporting equivalent drop-out rates for in-hospital [88] and post-discharge training interventions [116]. Furthermore, at baseline there was no significant difference in the DEMMI score between those who remained in the study and those who dropped out. In the present study, participants in both groups choosing to refrain from further participation said they lacked time and felt that the main entrance of their house had turned into a revolving door of health professionals. Also, older medical patients that may benefit from physical rehabilitation during and after hospitalization may have barriers preventing exercise participation. In a study by Brown et al. [29] reporting difficulties in recruiting acutely admitted older medical patients, those declining to participate expressed that they did not feel like exercising or did not believe they could. The reasons for non-participation in the present study were e.g. lack of time, believing oneself to be sufficiently active, or disbelief in the effect of exercise. A large number of patients were excluded from our study or declined to participate, leaving us with a very selective group of older medical patients. However, similar or lower consent rates have been reported in previous studies in older medical patients $[29,43,117]$. This underlines the difficulties in recruiting patients in the acute setting and limits the generalizability of the results. In the intervention group, only $43 \%$ were very compliant with the intervention, which may explain the lack of effect seen in this study. This level of compliance, though, is in line with a study in acutely admitted geriatric patients [87] and stresses the challenges in maintaining acutely admitted older adults in training interventions. Also, we experienced a large amount of missing data in our study, due among other reasons to the high number of drop outs. In addition, several ActivPals were lost during the intervention period, which may have affected the results. Furthermore, a limitation of our study was that we did not measure the rate of perceived exertion as an indicator of performance intensity. However, in a feasibility study preceding the present study, we found that the subjectively perceived effort, assessed by the BORG score, when performing the exercises used in the present study, corresponded well with our aim of 8-12 repetitions being equivalent with $60-70 \%$ exertion [51]. Thus, perceived exertion was not assessed in the present study.

\section{Conclusions}

A simple, low technology, supervised strength training program for the lower extremities, combined with posttraining oral protein supplementation initiated during hospitalization and continued in the home setting for 4 weeks after discharge, was not superior to usual care in the effect on change in mobility 4 weeks after discharge in older medical patients admitted with acute illness. For the secondary outcome, the daily number of steps, good compliance with the intervention resulted in a greater daily number of steps.

\section{Supplementary information}

Supplementary information accompanies this paper at https://doi.org/10. 1186/s13063-019-3720-x.

Additional file 1. Number of imputations at different time points for the primary and secondary outcomes. The table shows the number of imputations used at each assessment point for the primary and the secondary outcomes for both the intention-to-treat analysis and the per-protocol analysis.

\section{Abbreviations}

ADL: Activities of daily living; BI: The Barthel Index 20; Cl: Confidence interval; CONSORT: Consolidated Standards of Reporting Trials; COPD: Chronic obstructive pulmonary disease; DEMMI: The De Morton Mobility Index; Heelraise: Heel raise exercise; HG: Habitual gait speed; HGS: Hand-grip strength; ICD-10: The International Classification of Diseases, 10th Edition;

IQR: Interquartile range; ITT: Intention to treat; LOS: Length of stay; NMS: New Mobility Score; PP: Per protocol; RM: Repetition maximum; SD: Standard deviation; STAND: Sit-to-stand exercise; STS: The 30-s sit-to-stand test; VRS: The Verbal Ranking Scale

\section{Acknowledgements}

We thank the municipalities of Copenhagen and Broendby, the Emergency Department and the Department of Physiotherapy at Copenhagen University Hospital, Hvidovre, Denmark, for participating in the study, and all physiotherapists involved in performing the assessments and supervising the exercise sessions. We are grateful to the funding bodies, who supported this study: the Danish Ministry of Health Danish Regions/The Danish Health

Confederation, the Lundbeck Foundation, (UCSF), the Research Foundation of Hvidovre Hospital, the Capital Region of Copenhagen, The Danish

Foundation for Research in Physiotherapy, and Nutricia A/S for donating the 
protein supplements for the study. This study was performed in collaboration with the Optimized Senior Patient Program (Optimed)and Physical Medicine \& Rehabilitation Research-Copenhagen (PMR-C) at Copenhagen University Hospital Hvidovre, Hvidovre, Denmark.

\section{Authors' contributions}

MMP, TB, JP, OA, and NB designed the study in collaboration with the municipalities of Copenhagen and Broendby. MMP was the primary investigator and project leader and responsible for patient recruitment and data management. HGJL helped in training the included patients. PSJ was responsible for the randomization list. MMP and JP were responsible for analyzing data. MMP wrote the first manuscript draft. Hereafter, all authors revised the manuscript critically for important intellectual content, and all authors approved the final version to be submitted for publication. The STAND-Cph collaborative group (in alphabetical order by name): Ove Andersen, Clinical Research Centre and The Emergency Department, Copenhagen University Hospital, Hvidovre, Denmark and Department of Clinical Medicine, Faculty of Health and Medical Sciences, University of Copenhagen, Copenhagen, Denmark; Thomas Bandholm, Clinical Research Centre, Copenhagen University Hospital Hvidovre, Hvidovre, Denmark and Department of Physiotherapy and Department of Orthopaedic Surgery, Copenhagen University Hospital Hvidovre, Hvidovre, Denmark; Jonathan F Bean, New England Geriatric Research Education and Clinical Center, VA Boston Healthcare System, Boston, MA and Spaulding Rehabilitation Hospital, Boston, MA and Department of Physical Medicine and Rehabilitation, Harvard Medical School, Boston, MA; Nina Beyer, Department of Physical and Occupational Therapy, Bispebjerg and Frederiksberg Hospital, University of Copenhagen, Denmark, and Department of Clinical Medicine, University of Copenhagen, Denmark; Ann Christine Bodilsen, Clinical Research Centre, Copenhagen University Hospital, Hvidovre, Denmark; Rasmus Brødsgaard, Clinical Research Centre, Copenhagen University Hospital, Hvidovre, Denmark; Jette Christensen, Department of Physical- and Occupational therapy, Copenhagen University Hospital Hvidovre, Hvidovre, Denmark; Line Due

Christensen, Clinical Research Centre, Copenhagen University Hospital, Hvidovre, Denmark; Christina Dahl, Clinical Research Centre, Copenhagen University Hospital, Hvidovre, Denmark; Lars Damkjær, Department of Rehabilitation, Municipality of Copenhagen, Copenhagen, Denmark; Simon Hegnsvad, Department of Rehabilitation, Municipality of Copenhagen, Copenhagen, Denmark; Pia Søe Jensen, Clinical Research Centre, Copenhagen University Hospital, Hvidovre, Denmark and Department of Ortopaedic Surgery, Copenhagen University Hospital, Hvidovre, Denmark; Karen Dalsgaard Jepsen, Department of Rehabilitation, Municipality of Broendby, Broendby, Denmark; Helle Gybel Juul-Larsen, Clinical Research Centre, Copenhagen University Hospital, Hvidovre, Denmark; Louise LawsonSmith, Clinical Research Centre, Copenhagen University Hospital, Hvidovre, Denmark; Morten Ledertoug, Department of Physiotherapy, Copenhagen University Hospital Hvidovre, Hvidovre, Denmark; Robert-Jan Nienhuis, Department of Physical- and Occupational therapy, Copenhagen University Hospital Hvidovre,

Hvidovre, Denmark; Sanne Stiberg, Department of Physical- and Occupational therapy, Copenhagen University Hospital Hvidovre, Hvidovre, Denmark; Maja Pedersen,

Clinical Research Centre, Copenhagen University Hospital, Hvidovre, Denmark; Mette Merete Pedersen, Clinical Research Centre, Copenhagen University Hospital Hvidovre, Hvidovre, Denmark; Frida Margareta Persson, Department of

Physical- and Occupational therapy, Copenhagen University Hospital Hvidovre, Hvidovre, Denmark; Janne Petersen, Clinical Research Centre, Copenhagen University

Hospital, Hvidovre, Denmark and Section of Biostatistics, Department of Public Health, University of Copenhagen, Denmark; Trine Rehfeld Lind, Department of Physical- and Occupational therapy, Copenhagen University Hospita Hvidovre, Hvidovre, Denmark; Rikke Friis Knudsen, Department of Physicaland Occupational therapy, Copenhagen University

Hospital Hvidovre, Hvidovre, Denmark; Gitte Salomonsen, Department of Rehabilitation, Municipality of Copenhagen, Copenhagen, Denmark; Bettina Solgaard, Department of Rehabilitation, Municipality of Broendby, Broendby, Denmark; Lisbeth Sommer, Department of Rehabilitation, Municipality of Broendby, Broendby, Denmark; Maria Therese Stage, Department of Physical- and Occupational therapy, Copenhagen University Hospital
Hvidovre, Hvidovre, Denmark; Berit Thorslund, Department of Rehabilitation, Municipality of Copenhagen, Copenhagen, Denmark; Marie West, Department of Rehabilitation, Municipality of Broendby, Broendby, Denmark; Jade Kavanaugh Wulff, Department of Physical- and Occupational therapy, Copenhagen University Hospital Hvidovre, Hvidovre, Denmark

\section{Funding}

This study was funded by the Danish Ministry of Health (grant number 9170), Danish Regions/The Danish Health Confederation; the Lundbeck Foundation (UCSF) (grant numbers FP 07/2012, FP 48/2012 and FP 61/2013); the Research Foundation of Hvidovre Hospital; the Capital Region of Copenhagen; and The Danish Foundation for Research in Physiotherapy.

\section{Availability of data and materials}

The datasets generated and/or analyzed during the current study are not publicly available due to regulations set out by the Danish Data Protection Agency regarding data anonymization but are available from the corresponding author on reasonable request.

\section{Ethics approval and consent to participate}

All participants gave written informed consent before participation and the study procedures were approved by the Ethics Committee of the Capital Region of Denmark (H-2-2012-115) and by the Danish Data Protection Agency (2007-58-0015).

\section{Consent for publication}

Not applicable.

\section{Competing interests}

The authors declare that they have no competing interests. The funding bodies have had no authority over study design, collection and interpretation of data, or the writing of the manuscript.

\section{Author details}

${ }^{1}$ Clinical Research Centre, Copenhagen University Hospital Hvidovre, Kettegaard Alle 30, 2650 Hvidovre, Denmark. ${ }^{2}$ Section of Biostatistics, Department of Public Health, University of Copenhagen, Øster Farimagsgade 5 Entrance B, 2nd floor, 1014 Copenhagen K, Denmark. ${ }^{3}$ Center for Clinical Research and Prevention, Copenhagen University Hospital, Bispebjerg and Frederiksberg, Bispebjerg Bakke 23, 2400 Copenhagen N, Denmark. ${ }^{4}$ Department of Physical and Occupational Therapy, Copenhagen University Hospital, Bispebjerg and Frederiksberg, Bispebjerg Bakke 23, 2400 Copenhagen N, Denmark. ${ }^{5}$ Department of Clinical Medicine, Faculty of Health and Medical Sciences, University of Copenhagen, Blegdamsvej 3B, 2200 Copenhagen N, Denmark. ${ }^{6}$ Department of Orthopaedic Surgery, Copenhagen University Hospital, Kettegaard Alle 30, 2650 Hvidovre, Denmark. 7The Emergency Department, Copenhagen University Hospital, Kettegaard Alle 30, 2650 Hvidovre, Denmark. ${ }^{8}$ Department of Physical- and Occupational Therapy, Copenhagen University Hospital Hvidovre, Kettegaard Alle 30, 2650 Hvidovre, Denmark.

Received: 24 January 2019 Accepted: 13 September 2019 Published online: 28 November 2019

\section{References}

1. Fried TR, Tinetti ME, lannone L, O'Leary JR, Towle V, Van Ness PH. Health outcome prioritization as a tool for decision making among older persons with multiple chronic conditions. Arch Intern Med. 2011;171:1854-6.

2. Åberg AC, Sidenvall B, Hepworth $M$, O'Reilly $K$, Lithell H. On loss of activity and independence, adaptation improves life satisfaction in old age: a qualitative study of patients' perceptions. Qual Life Res. 2005;14:1111-25.

3. Krumholz HM. Post-hospital syndrome-an acquired, transient condition of generalized risk. N Engl J Med. 2013;368:100-2.

4. Kortebein P. Rehabilitation for hospital-associated deconditioning. Am J Phys Med Rehabil. 2009;88:66-77. https://doi.org/10.1097/PHM. 0b013e3181838f70.

5. Gill TM, Allore H, Guo Z. The deleterious effects of bed rest among community-living older persons. J Gerontol A Biol Sci Med Sci. 2004;59: M755-61. 
6. Lafont C, Gérard S, Voisin T, Pahor M, Vellas B. Reducing "iatrogenic disability" in the hospitalized frail elderly. J Nutr Health Aging. 2011;15: 645-60.

7. Admi $\mathrm{H}$, Shadmi $\mathrm{E}$, Baruch $\mathrm{H}$, Zisberg A. From research to reality: minimizing the effects of hospitalization on older adults. Rambam Maimonides Med J. 2015;6:e0017.

8. Brown CJ, Friedkin RJ, Inouye SK. Prevalence and outcomes of low mobility in hospitalized older patients. J Am Geriatr Soc. 2004;52:1263-70.

9. Zisberg A, Shadmi E, Gur-Yaish N, Tonkikh O, Sinoff G. Hospital-associated functional decline: the role of hospitalization processes beyond individual risk factors. J Am Geriatr Soc. 2015;63:55-62.

10. Sourdet S, Lafont C, Rolland Y, Nourhashemi F, Andrieu S, Vellas B. Preventable iatrogenic disability in elderly patients during hospitalization. J Am Med Dir Assoc. 2015;16:674-81.

11. Pedersen MM, Bodilsen AC, Petersen J, Beyer N, Andersen O, Lawson-Smith $L$, et al. Twenty-four-hour mobility during acute hospitalization in older medical patients. J Gerontol A Biol Sci Med Sci. 2013 March:68(3):331-7.

12. Villumsen $M$, Jorgensen MG, Andreasen J, Rathleff MS, Mølgaard CM. Very low levels of physical activity in older patients during hospitalization at an acute geriatric ward - a prospective cohort study. J Aging Phys Act. 2015;23:542-9.

13. Callen BL, Mahoney JE, Grieves CB, Wells TJ, Enloe M. Frequency of hallway ambulation by hospitalized older adults on medical units of an academic hospital. Geriatr Nur (Lond). 2004;25:212-7.

14. Fisher SR, Goodwin JS, Protas EJ, Kuo Y-F, Graham JE, Ottenbacher K, et al. Ambulatory activity of older adults hospitalized with acute medical illness. Am Geriatr Soc. 2011;59:91-5. https://doi.org/10.1111/j.1532-5415.2010.03202.x.

15. Cattanach N, Sheedy R, Gill S, Hughes A. Physical activity levels and patients' expectations of physical activity during acute general medical admission. Intern Med J. 2014;44:501-4. https://doi.org/10.1111/imj.12411.

16. Hvid L, Aagaard P, Justesen L, Bayer ML, Andersen JL, Ørtenblad N, et al. Effects of aging on muscle mechanical function and muscle fiber morphology during short-term immobilization and subsequent retraining. J Appl Physiol (1985). 2010;109:1628-34 Bethesda Md.

17. Kortebein P, Ferrando A, Lombeida J, Wolfe R, Evans WJ. Effect of 10 days of bed rest on skeletal muscle in healthy older adults. JAMA. 2007;297:1772-4.

18. Kortebein P, Symons TB, Ferrando A, Paddon-Jones D, Ronsen O, Protas E, et al. Functional impact of 10 days of bed rest in healthy older adults. J Gerontol A Biol Sci Med Sci. 2008;63:1076-81.

19. Coker RH, Hays NP, Williams RH, Wolfe RR, Evans WJ. Bed rest promotes reductions in walking speed, functional parameters, and aerobic fitness in older, healthy adults. J Gerontol A Biol Sci Med Sci. 2014. https://doi.org/10. 1093/gerona/glu123.

20. Drummond MJ, Dickinson JM, Fry CS, Walker DK, Gundermann DM, Reidy PT, et al. Bed rest impairs skeletal muscle amino acid transporter expression, mTORC1 signaling, and protein synthesis in response to essential amino acids in older adults. AJP Endocrinol Metab. 2012;302:E1113-22. https://doi. org/10.1152/ajpendo.00603.2011.

21. Alley DE, Koster A, Mackey D, Cawthon P, Ferrucci L, Simonsick EM, et al. Hospitalization and change in body composition and strength in a populationbased cohort of older persons. J Am Geriatr Soc. 2010;58:2085-91.

22. Breen L, Stokes KA, Churchward-Venne TA, Moore DR, Baker SK, Smith K, et al. Two weeks of reduced activity decreases leg lean mass and induces "anabolic resistance" of myofibrillar protein synthesis in healthy elderly. J Clin Endocrinol Metab. 2013:98:2604-12.

23. LeBlanc AD, Schneider VS, Evans HJ, Pientok C, Rowe R, Spector E. Regional changes in muscle mass following 17 weeks of bed rest. J Appl Physiol (1985). 1992;73:2172-8 Bethesda Md.

24. Suetta C, Hvid LG, Justesen L, Christensen U, Neergaard K, Simonsen L, et al. Effects of aging on human skeletal muscle after immobilization and retraining. J Appl Physiol. 2009;107:1172-80. https://doi.org/10.1152/ japplphysiol.00290.2009.

25. Singh MAF. Exercise comes of age: rationale and recommendations for a geriatric exercise prescription. J Gerontol A Biol Sci Med Sci. 2002;57:M262-82.

26. Bean JF, Leveille SG, Kiely DK, Bandinelli S, Guralnik JM, Ferrucci L. A comparison of leg power and leg strength within the InCHIANTI study: which influences mobility more? J Gerontol A Biol Sci Med Sci. 2003;58:728-33.

27. Boyd CM, Landefeld CS, Counsell SR, Palmer RM, Fortinsky RH, Kresevic D, et al. Recovery of activities of daily living in older adults after hospitalization for acute medical illness. J Am Geriatr Soc. 2008;56:2171-9. https://doi.org/ 10.1111/j.1532-5415.2008.02023.x.
28. Hoyer EH, Needham DM, Atanelov L, Knox B, Friedman M, Brotman DJ. Association of impaired functional status at hospital discharge and subsequent rehospitalization. J Hosp Med. 2014;9:277-82.

29. Brown CJ, Peel C, Bamman MM, Allman RM. Exercise program implementation proves not feasible during acute care hospitalization. J Rehabil Res Dev. 2006:43:939-46.

30. Kosse NM, Dutmer AL, Dasenbrock L, Bauer JM, Lamoth CJC. Effectiveness and feasibility of early physical rehabilitation programs for geriatric hospitalized patients: a systematic review. BMC Geriatr. 2013;13:107

31. Andreasen J, Lund $H$, Aadahl M, Sørensen EE. The experience of daily life of acutely admitted frail elderly patients one week after discharge from the hospital. Int J Qual Stud Health Well-Being. 2015;10:27370.

32. Liu CJ, Latham NK. Progressive resistance strength training for improving physical function in older adults. Cochrane Database Syst Rev. 2009;(3)Art. No.: CD002759. https://doi.org/10.1002/14651858.CD002759.pub2.

33. Koopman R, van Loon LC. Aging, exercise, and muscle protein metabolism J Appl Physiol (1985). 2009;106:2040-8 Bethesda Md.

34. Fiatarone MA, O'Neill EF, Ryan ND, Clements KM, Solares GR, Nelson ME, et al. Exercise training and nutritional supplementation for physical frailty in very elderly people. N Engl J Med. 1994;330:1769-75.

35. Stewart VH, Saunders DH, Greig CA. Responsiveness of muscle size and strength to physical training in very elderly people: a systematic review. Scand J Med Sci Sports. 2014;24:e1-10.

36. Valenzuela T. Efficacy of progressive resistance training interventions in older adults in nursing homes: a systematic review. J Am Med Dir Assoc. 2012;13:418-28. https://doi.org/10.1016/j.jamda.2011.11.001.

37. Olivetti L, Schurr K, Sherrington C, Wallbank G, Pamphlett P, Kwan MM-S, et al. A novel weight-bearing strengthening program during rehabilitation of older people is feasible and improves standing up more than a nonweight-bearing strengthening program: a randomised trial. Aust J Physiother. 2007;53:147-53. https://doi.org/10.1016/S0004-9514(07)70021-1.

38. Steib S, Schoene D, Pfeifer K. Dose-response relationship of resistance training in older adults. Med Sci Sports Exerc. 2010;42:902-14. https://doi. org/10.1249/MSS.0b013e3181c34465.

39. Raymond MJ, Bramley-Tzerefos RE, Jeffs KJ, Winter A, Holland AE. Systematic review of high-intensity progressive resistance strength training of the lower limb compared with other intensities of strength training in older adults. Arch Phys Med Rehabil. 2013;94:1458-72. https://doi.org/10.1016/j.apmr.2013.02.022.

40. de Vries NM, van Ravensberg CD, Hobbelen JSM, Olde Rikkert MGM Staal JB, Nijhuis-van der Sanden MWG. Effects of physical exercise therapy on mobility, physical functioning, physical activity and quality of life in community-dwelling older adults with impaired mobility, physical disability and/or multi-morbidity: a meta-analysis. Ageing Res Rev. 2012:11:136-49.

41. Seynnes $O$, Fiatarone Singh MA, Hue $O$, Pras $P$, Legros $P$, Bernard PL. Physiological and functional responses to low-moderate versus highintensity progressive resistance training in frail elders. J Gerontol A Biol Sci Med Sci. 2004;59:503-9.

42. De Morton NA, Keating JL, Jeffs K. Exercise for acutely hospitalised older medical patients. Cochrane Database Syst Rev. 2009;1. https://doi.org/10. 1002/14651858.CD005955.pub2.

43. Siebens $\mathrm{H}$, Aronow $\mathrm{H}$, Edwards D, Ghasemi $\mathrm{Z}$. A randomized controlled trial of exercise to improve outcomes of acute hospitalization in older adults. J Am Geriatr Soc. 2000:48:1545-52.

44. Courtney MD, Edwards HE, Chang AM, Parker AW, Finlayson K, Bradbury C, et al. Improved functional ability and independence in activities of daily living for older adults at high risk of hospital readmission: a randomized controlled trial. J Eval Clin Pract. 2012;18:128-34. https://doi.org/10.1111/j. $1365-2753.2010 .01547 x$

45. Esmarck B, Andersen JL, Olsen S, Richter EA, Mizuno M, Kjaer M. Timing of post exercise protein intake is important for muscle hypertrophy with resistance training in elderly humans. J Physiol. 2001;535(Pt 1):301-11.

46. Yang Y, Breen L, Burd NA, Hector AJ, Churchward-Venne TA, Josse AR, et al. Resistance exercise enhances myofibrillar protein synthesis with graded intakes of whey protein in older men. Br J Nutr. 2012;108:1780-8.

47. Cermak NM, Res PT, de Groot LCPGM, Saris WHM, van Loon LC. Protein supplementation augments the adaptive response of skeletal muscle to resistance-type exercise training: a meta-analysis. Am J Clin Nutr. 2012;96:1454-64.

48. Pedersen MM, Petersen J, Beyer N, Damkjær L, Bandholm T. Supervised progressive cross-continuum strength training compared with usual care in 
older medical patients: study protocol for a randomized controlled trial (the STAND-Cph trial). Trials. 2016;17:176.

49. Boutron I, Moher D, Altman DG, Schulz KF, Ravaud P. Extending the CONSORT statement to randomized trials of nonpharmacologic treatment: explanation and elaboration. Ann Intern Med. 2008;148:295-309. https://doi. org/10.7326/0003-4819-148-4-200802190-00008.

50. Slade SC, Dionne CE, Underwood M, Buchbinder R. Consensus on Exercise Reporting Template (CERT): explanation and elaboration statement. Br J Sports Med. 2016;50:1428-37. https://doi.org/10.1136/bjsports-2016-096651.

51. Pedersen MM, Petersen J, Bean JF, Damkjaer L, Juul-Larsen HG, Andersen O, et al. Feasibility of progressive sit-to-stand training among older hospitalized patients. PeerJ. 2015;3:e1500.

52. Kraemer WJ, Ratamess NA. Fundamentals of resistance training: progression and exercise prescription. Med Sci Sports Exerc. 2004;36:674-88. https://doi. org/10.1249/01.MSS.0000121945.36635.61.

53. de Morton NA, Davidson M, Keating JL. The de Morton Mobility Index (DEMMI): an essential health index for an ageing world. Health Qual Life Outcomes. 2008;6:63. https://doi.org/10.1186/1477-7525-6-63.

54. Davenport SJ, de Morton NA. Clinimetric properties of the de Morton Mobility Index in healthy, community-dwelling older adults. Arch Phys Med Rehabil. 2011;92:51-8.

55. de Morton N, Lane K. Validity and reliability of the de Morton Mobility Index in the subacute hospital setting in a geriatric evaluation and management population. J Rehabil Med. 2010;42:956-61. https://doi.org/10.2340/ 16501977-0626.

56. de Morton NA, Davidson M, Keating JL. Validity, responsiveness and the minimal clinically important difference for the de Morton Mobility Index (DEMMI) in an older acute medical population. BMC Geriatr. 2010;10:72.

57. Macri EM, Lewis JA, Khan KM, Ashe MC, de Morton NA. The de morton mobility index: normative data for a clinically useful mobility instrument. J Aging Res. 2012;2012:353252.

58. Grant PM, Ryan CG, Tigbe WW, Granat MH. The validation of a novel activity monitor in the measurement of posture and motion during everyday activities, Br J Sports Med. 2006;40:992-7. https://doi.org/10.1136/bjsm.2006.030262.

59. Taraldsen K, Askim T, Sletvold O, Einarsen EK, Bjåstad KG, Indredavik B, et al. Evaluation of a body-worn sensor system to measure physical activity in older people with impaired function. Phys Ther. 2011;91:277-85.

60. Ryan CG, Grant PM, Tigbe WW, Granat MH. The validity and reliability of a novel activity monitor as a measure of walking. Br J Sports Med. 2006;40:779-84.

61. Grant PM, Dall PM, Mitchell SL, Granat MH. Activity-monitor accuracy in measuring step number and cadence in community-dwelling older adults. J Aging Phys Act. 2008;16:201-14.

62. Kanoun N. Validation of the ActivPAL activity monitor as a measure of walking at pre-determined slow walking speeds in a healthy population in a controlled setting. Reinvention J Undergrad Res Vol 2 Issue 2. 2009. http:// www.warwick.ac.uk/go/reinventionjournal/issues/volume2issue2/kanoun. Date accessed 30 Mar 2016.

63. McCullagh R, Brady NM, Dillon C, Horgan NF. A review of the accuracy and utility of motion sensors to measure physical activity of frail, older hospitalized patients. J Aging Phys Act. 2016;24:465-75. https://doi.org/10. 1123/japa.2014-0190.

64. Bohannon RW. Measuring knee extensor muscle strength. Am J Phys Med Rehabil. 2001;80:13-8.

65. Wang C-Y, Olson SL, Protas EJ. Test-retest strength reliability: hand-held dynamometry in community-dwelling elderly fallers. Arch Phys Med Rehabil. 2002;83:811-5. https://doi.org/10.1053/apmr.2002.32743.

66. Jones CJ, Rikli RE, Beam WC. A 30-s chair-stand test as a measure of lower body strength in community-residing older adults. Res Q Exerc Sport. 1999; 70:113-9.

67. Guralnik JM, Simonsick EM, Ferrucci L, Glynn RJ, Berkman LF, Blazer DG, et al. A short physical performance battery assessing lower extremity function: association with self-reported disability and prediction of mortality and nursing home admission. J Gerontol. 1994;49:M85-94.

68. Guralnik JM, Ferrucci L, Pieper CF, Leveille SG, Markides KS, Ostir GV, et al. Lower extremity function and subsequent disability: consistency across studies, predictive models, and value of gait speed alone compared with the short physical performance battery. J Gerontol A Biol Sci Med Sci. 2000;55:M221-31.

69. Lauretani F, Russo CR, Bandinelli S, Bartali B, Cavazzini C, Di lorio A, et al. Age-associated changes in skeletal muscles and their effect on mobility: an operational diagnosis of sarcopenia. J Appl Physiol (1985). 2003:95:1851-60 Bethesda Md.
70. Wade DT, Collin C. The Barthel ADL Index: a standard measure of physical disability? Int Disabil Stud. 1988;10:64-7.

71. Kristensen MT, Foss NB, Kehlet H. Timed Up and Go and New Mobility Score as predictors of function six months after hip fracture. Ugeskr Laeger. 2005;167(35):3297-300

72. Parker MJ, Palmer CR. A new mobility score for predicting mortality after hip fracture. J Bone Joint Surg Br. 1993;75:797-8.

73. Foss NB, Kristensen MT, Kehlet H. Prediction of postoperative morbidity, mortality and rehabilitation in hip fracture patients: the cumulated ambulation score. Clin Rehabil. 2006;20:701-8. https://doi.org/10.1191/0269215506cre987oa.

74. Katzman R, Brown T, Fuld P, Peck A, Schechter R, Schimmel H. Validation of a short Orientation-Memory-Concentration Test of cognitive impairment. Am J Psychiatry. 1983;140:734-9.

75. Folstein MF, Folstein SE, McHugh PR. "Mini-mental state". A practical method for grading the cognitive state of patients for the clinician. J Psychiatr Res. 1975;12:189-98.

76. Yesavage JA, Brink TL, Rose TL, Lum O, Huang V, Adey M, et al. Development and validation of a geriatric depression screening scale: a preliminary report. J Psychiatr Res. 1982;17:37-49.

77. Rabin R, de Charro F. EQ-5D: a measure of health status from the EuroQol Group. Ann Med. 2001;33:337-43.

78. Vellas B, Guigoz Y, Garry PJ, Nourhashemi F, Bennahum D, Lauque S, et al. The Mini Nutritional Assessment (MNA) and its use in grading the nutritional state of elderly patients. Nutr Burbank Los Angel Cty Calif. 1999;15:116-22.

79. Schnohr P, Scharling H, Jensen JS. Changes in leisure-time physical activity and risk of death: an observational study of 7,000 men and women. Am J Epidemiol. 2003;158:639-44.

80. Saltin B, Grimby G. Physiological analysis of middle-aged and old former athletes. Comparison with still active athletes of the same ages. Circulation. 1968:38:1104-15.

81. Melzack R. The McGill Pain Questionnaire: major properties and scoring methods. Pain. 1975;1:277-99.

82. Catananti C, Gambassi G. Pain assessment in the elderly. Surg Oncol. 2010; 19:140-8. https://doi.org/10.1016/j.suronc.2009.11.010.

83. Charlson ME, Pompei P, Ales KL, MacKenzie CR. A new method of classifying prognostic comorbidity in longitudinal studies: development and validation J Chronic Dis. 1987;40:373-83.

84. World Health Organization. International Statistical Classification of Diseases and Related Health Problems 10th Revision 2015. Geneva: World Health Organization; 2015.

85. Graham JW, Olchowski AE, Gilreath TD. How many imputations are really needed? Some practical clarifications of multiple imputation theory. Prev Sci Off J Soc Prev Res. 2007;8:206-13.

86. Klausen HH, Bodilsen AC, Petersen J, Bandholm T, Haupt T, Sivertsen DM, et al. How inflammation underlies physical and organ function in acutely admitted older medical patients. Mech Ageing Dev. 2017;164:67-75. https:// doi.org/10.1016/j.mad.2017.04.005.

87. Oestergaard AS, Mathiesen MH, Karlsen A, Turtumoeygaard IF, Vahlgren J, Kjaer $M$, et al. In acutely admitted geriatric patients, offering increased physical activity during hospitalization decreases length of stay and can improve mobility. Transl Sports Med. 2018;1:46-53. https://doi.org/10.1002/tsm2.2.

88. Tibaek S, Andersen CW, Pedersen SF, Rudolf KS. Does progressive resistance strength training as additional training have any measured effect on functional outcomes in older hospitalized patients? A single-blinded randomized controlled trial. Clin Rehabil. 2013:0269215513501524. https:// doi.org/10.1177/0269215513501524

89. Hvid LG, Suetta C, Nielsen JH, Jensen MM, Frandsen U, Ørtenblad N, et al. Aging impairs the recovery in mechanical muscle function following 4 days of disuse. Exp Gerontol. 2014;52:1-8.

90. Jadczak AD. Effectiveness of exercise interventions on physical function in community-dwelling frail older people: an umbrella review of systematic reviews. JBI Database Syst Rev Implement Rep. 2018;16:752-75.

91. Hruda KV, Hicks AL, McCartney N. Training for muscle power in older adults: effects on functional abilities. Can J Appl Physiol Rev Can Physiol Appl. 2003;28:178-89.

92. Chandler JM, Duncan PW, Kochersberger G, Studenski S. Is lower extremity strength gain associated with improvement in physical performance and disability in frail, community-dwelling elders? Arch Phys Med Rehabil. 1998;79:24-30.

93. Borde R, Hortobágyi T, Granacher U. Dose-response relationships of resistance training in healthy old adults: a systematic review and meta-analysis. Sports Med. 2015;45:1693-720. https://doi.org/10.1007/s40279-015-0385-9. 
94. de Morton NA, Meyer C, Moore KJ, Dow B, Jones C, Hill K. Validation of the de Morton Mobility Index (DEMMI) with older community care recipients. Australas J Ageing. 2011;30:220-5.

95. De Buyser SL, Petrovic M, Taes YE, Vetrano DL, Corsonello A, Volpato S, et al. Functional changes during hospital stay in older patients admitted to an acute care ward: a multicenter observational study. PLoS One. 2014;9:e96398.

96. Bodilsen AC, Pedersen MM, Petersen J, Beyer N, Andersen O, Smith LL, et al. Acute hospitalization of the older patient: changes in muscle strength and functional performance during hospitalization and 30 days after discharge. Am J Phys Med Rehabil. 2013;92(9):789-96. https://doi. org/10.1097/PHM.0b013e31828cd2b6.

97. Hasegawa R, Islam MM, Lee SC, Koizumi D, Rogers ME, Takeshima N Threshold of lower body muscular strength necessary to perform ADL independently in community-dwelling older adults. Clin Rehabil. 2008;22: 902-10. https://doi.org/10.1177/0269215508094713.

98. Manini TM, Visser M, Won-Park S, Patel KV, Strotmeyer ES, Chen H, et al. Knee extension strength cutpoints for maintaining mobility. J Am Geriatr Soc. 2007;55:451-7.

99. Quadri P, Tettamanti M, Bernasconi S, Trento F, Loew F. Lower limb function as predictor of falls and loss of mobility with social repercussions one year after discharge among elderly inpatients. Aging Clin Exp Res. 2005;17:82-9.

100. den Ouden MEM, Schuurmans MJ, Arts IEMA, van der Schouw YT. Physical performance characteristics related to disability in older persons: a systematic review. Maturitas. 2011;69:208-19.

101. Rantanen T, Avlund K, Suominen H, Schroll M, Frändin K, Pertti E. Muscle strength as a predictor of onset of ADL dependence in people aged 75 years. Aging Clin Exp Res. 2002;14(3 Suppl):10-5

102. Cooper R, Kuh D, Hardy R, Mortality Review Group, on behalf of the FALCon and HALCyon study teams. Objectively measured physical capability levels and mortality: systematic review and meta-analysis. BMJ. 2010;341:c4467. https://doi.org/10.1136/bmj.c4467.

103. Goins RT, Jones J, Schure M, Rosenberg DE, Phelan EA, Dodson S, et al. Older adults' perceptions of mobility: a metasynthesis of qualitative studies. Gerontologist. 2015;55(6):929-42. https://doi.org/10.1093/geront/gnu014.

104. Agmon M, Zisberg A, Gil E, Rand D, Gur-Yaish N, Azriel M. Association between 900 steps a day and functional decline in older hospitalized patients. JAMA Intern Med. 2017;177:272-4. https://doi.org/10.1001/ jamainternmed.2016.7266.

105. Floegel TA, Dickinson JM, DerAnanian C, McCarthy M, Hooker SP, Buman MP. Association of posture and ambulation with function 30 days after hospital discharge in older Adults with heart failure. J Card Fail. 2018;24: 126-30. https://doi.org/10.1016/j.cardfail.2018.01.001.

106. McCullagh R, Dillon C, Dahly D, Horgan NF, Timmons S. Walking in hospital is associated with a shorter length of stay in older medical inpatients. Physiol Meas. 2016;37:1872-84. https://doi.org/10.1088/09673334/37/10/1872.

107. Ostir GV, Berges IM, Kuo Y-F, Goodwin JS, Fisher SR, Guralnik JM. Mobility activity and its value as a prognostic indicator of survival in hospitalized older adults. J Am Geriatr Soc. 2013;61:551-7.

108. Fisher SR, Kuo Y-F, Sharma G, Raji MA, Kumar A, Goodwin JS, et al. Mobility after hospital discharge as a marker for 30-day readmission. J Gerontol A Biol Sci Med Sci. 2013;68:805-10.

109. Brown CJ, Williams BR, Woodby LL, Davis LL, Allman RM. Barriers to mobility during hospitalization from the perspectives of older patients and their nurses and physicians. J Hosp Med. 2007;2:305-13. https://doi. org/10.1002/jhm.209.

110. Kirk JW, Bodilsen AC, Tjørnhøj-Thomsen T, Pedersen MM, Bandholm T, Skov Husted R, et al. A tailored strategy for designing the WalkCopenhagen (WALK-Cph) intervention to increase mobility in hospitalised older medical patients: a protocol for the qualitative part of the WALK-Cph project. BMJ Open. 2018;8:e020272. https://doi.org/10. 1136/ bmjopen-2017-020272.

111. Franco MR, Howard K, Sherrington C, Ferreira PH, Rose J, Gomes JL, et al. Eliciting older people's preferences for exercise programs: a best-worst scaling choice experiment. J Physiother. 2015;61:34-41.

112. Falvey J, Mangione K, Stevens-Lapsley J. Rethinking hospital-associated deconditioning: proposed paradigm shift. Phys Ther. 2015;95(9):1307-15. https://doi.org/10.2522/ptj.20140511.

113. Burton $\mathrm{E}$, Lewin $\mathrm{G}$, Boldy D. Physical activity preferences of older home care clients. Int J Older People Nursing. 2015;10:170-8.
114. Rasmussen BB, Phillips SM. Contractile and nutritional regulation of human muscle growth. Exerc Sport Sci Rev. 2003;31:127-31.

115. Bauer J, Biolo G, Cederholm T, Cesari M, Cruz-Jentoft AJ, Morley JE, et al. Evidence-based recommendations for optimal dietary protein intake in older people: a position paper from the PROT-AGE Study Group. J Am Med Dir Assoc. 2013;14:542-59.

116. Timonen L, Rantanen T, Ryynänen OP, Taimela S, Timonen TE, Sulkava R. A randomized controlled trial of rehabilitation after hospitalization in frail older women: effects on strength, balance and mobility. Scand J Med Sci Sports. 2002;12:186-92.

117. Mallery LH, MacDonald EA, Hubley-Kozey CL, Earl ME, Rockwood K, Macknight $C$. The feasibility of performing resistance exercise with acutely ill hospitalized older adults. BMC Geriatr. 2003;3:3.

\section{Publisher's Note}

Springer Nature remains neutral with regard to jurisdictional claims in published maps and institutional affiliations.
Ready to submit your research? Choose BMC and benefit from:

- fast, convenient online submission

- thorough peer review by experienced researchers in your field

- rapid publication on acceptance

- support for research data, including large and complex data types

- gold Open Access which fosters wider collaboration and increased citations

- maximum visibility for your research: over $100 \mathrm{M}$ website views per year

At $\mathrm{BMC}$, research is always in progress.

Learn more biomedcentral.com/submissions 